\title{
Full-Field Displacement Measurements of Helicopter Rotor Blades Using Stereophotogrammetry
}

\author{
Chenglin Zuo $\mathbb{D}^{\text {D, }}$, Chunhua Wei $\mathbb{D}^{-}$, Jun Ma, Tingrui Yue, Lei Liu, and Zheyu Shi \\ Low Speed Aerodynamics Institute, China Aerodynamics Research and Development Center, Mianyang 621000, China
}

Correspondence should be addressed to Chunhua Wei; wch410204603@126.com

Received 23 September 2020; Revised 10 December 2020; Accepted 30 December 2020; Published 8 January 2021

Academic Editor: Ennes Sarradj

Copyright (C) 2021 Chenglin Zuo et al. This is an open access article distributed under the Creative Commons Attribution License, which permits unrestricted use, distribution, and reproduction in any medium, provided the original work is properly cited.

\begin{abstract}
This study presents a stereophotogrammetry approach to achieve full-field displacement measurements of helicopter rotor blades. The method is demonstrated in the wind tunnel test of a $2 \mathrm{~m}$ diameter rotor, conducted at the $5.5 \mathrm{~m} \times 4 \mathrm{~m}$ Aeroacoustic Wind Tunnel of China Aerodynamics Research and Development Center (CARDC). By arranging the retroreflective targets on the special hat installed directly above the rotor hub, the dynamic motion of the rotor shaft was tracked accurately, and a unified coordinate system was established on the rotor. Therefore, three-dimensional coordinates of instantaneously measured targets attached on the blade could be transformed to the unified rotor coordinate system, thereby providing a basis for consistently calculating the blade displacements at different test conditions. Moreover, location deviations of the blade caused by the vibration of the measuring system or the rotor due to freestream and rotor rotation were also effectively corrected through coordinate transformation. Comparisons of experimental and simulation results for a range of hover and forward flight conditions show good magnitude and trend agreements.
\end{abstract}

\section{Introduction}

Rotor is the crucial component of the helicopter, which is directly related to flight safety and flight quality. Imperfect rotor design will greatly affect the aerodynamic, balance, and dynamic response characteristics of the helicopter and generate unexpected blade displacements during its highspeed rotation. Therefore, detailed understanding of the rotor motion under dynamic loading due to rotation is of crucial importance, which can be used for the validation and improvement of the rotor's structure and aerodynamic characteristics, and further provides a great quantity of information for helicopter flight control system design [1-3].

Until now, a variety of methods have been developed to measure the displacements of rotating rotor blades. The traditional method achieves the measurements with strain gauges embedded in the rotor blades $[4,5]$. However, due to blade size limitations and the limited availability of rotating instrumentation channels, the number of possible sensors is usually insufficient to fully resolve the blade geometry. Additionally, fabrication of the instrumented blades is also difficult and costly.
With the rapid development of optical technology, stereophotogrammetry has been widely applied in blade displacement measurements. It can provide a fairly robust and accurate description of the blade geometry over its entire length, along with the additional benefit of reduced fabrication costs and sensor count. Three-Dimensional Point Tracking (3DPT) technique is usually used in stereophotogrammetry, which can identify and track the $3 \mathrm{D}$ coordinates of discrete points mounted on the rotor blades. Schneider [6] utilized the 3DPT technique to achieve the $3 \mathrm{D}$ reconstruction of visible targets attached on the rotor blades at the GermanDutch Wind Tunnel and successfully measured the blade position and deflection based on stereophotogrammetry for the first time. At the NFAC 40- by 80 -Foot Wind Tunnel, Straub et al. [7] introduced the stereophotogrammetry to achieve the displacement measurements of a full-scale rotor blade in quadrant one of its rotation range during a forward flight condition. Olson et al. [8] performed blade displacement measurements in quadrants one and two with fourcamera stereophotogrammetry during the full-scale wind tunnel testing of the UH-60A Airloads rotor. Subsequently, this test was further improved with eight cameras to achieve 


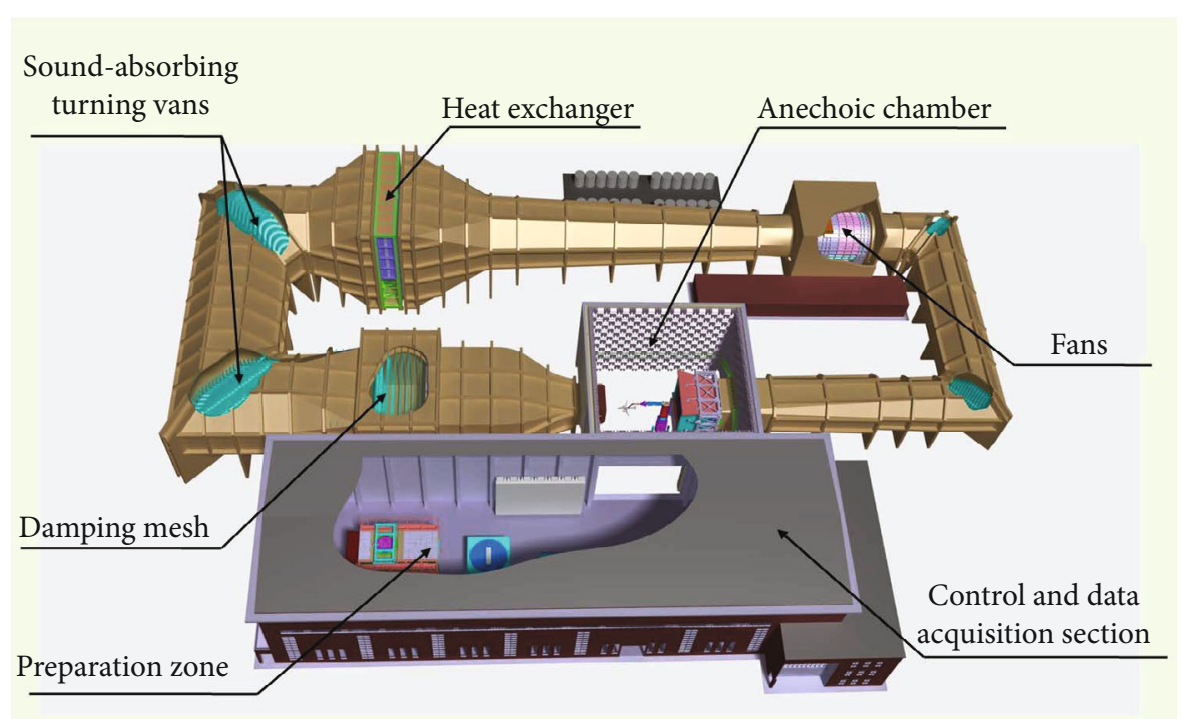

FIgURE 1: Overall structure of the $5.5 \mathrm{~m} \times 4 \mathrm{~m}$ Aeroacoustic Wind Tunnel at CARDC.

measurements in all quadrants at various advance ratios, thrust coefficients, and drive shaft angles $[9,10]$. In this test, forty-eight 2-inch-diameter retroreflective targets were installed on each blade, and the produced results closely matched the design parameters. Zuo et al. [11] applied coded markers as reference points of the rotor blades and measured the displacements and deformations of a $2 \mathrm{~m}$ diameter rotor. With the similar approach, Bernardini et al. [12] assessed the structural and inertial properties of two main rotor blades designed for ultralight helicopters. Lundstrom et al. [13] combined stereophotogrammetry and modal parameter identification to monitor the dynamics of a $10.1 \mathrm{~m}$ diameter helicopter rotor. Moreover, Dong et al. [14] integrated a stereovision system with a grid-pattern pressure-sensitive paint system, based on which simultaneous displacement and pressure measurements of a rotor blade were performed.

Another kind of stereophotogrammetry technique is Digital Image Correlation (DIC). By spraying random speckle pattern on the rotor blades, this approach can realize full-field and continuous measurements. Sirohi and Lawson [15] investigated the early application of stereoscopic DIC to the measurements of flap bending and torsion of rotating microhelicopter blades. Later, this work was extended to the displacement measurements of an extremely flexible rotor blade [16]. Wei et al. [17] proposed a videogrammetric system based on the DIC method and industrial close range photogrammetry technique, which solved the $3 \mathrm{D}$ motion and deformation parameters of a rotating blade. Uehara and Sirohi [18] performed the full-field displacement measurements and operational modal analysis of an extremely flexible rotor blade in hover. With the DIC technique, they successfully measured the time history of 3D displacements over the entire rotor blade at approximately 900 measurement locations. Furthermore, they used the developed time-resolved DIC method to achieve the transient blade displacement measurements of a coaxial rotor system [19]. Sousa et al. [20-22] employed the DIC method to measure the total displacements of a rotating RC helicopter blade and made further comparison with numerical simulation results. Besides, Poozesh et al. [23] and Lehnhoff et al. [24] also applied the DIC technique in the full-field displacement measurements of wind turbine rotor blades that have a quite large size.

Although a lot of works have been conducted on the displacement measurements of helicopter rotor blades, it is still a challenging task to obtain accurate measurement results in practical applications, e.g., the wind tunnel test. On the one hand, construction of the measuring system that can achieve full-field measurements of rotor motion in the wind tunnel is complicated due to the environmental constraints. On the other hand, because of the freestream and the rotor rotation, the vibration of the measuring system or the rotor is not ignorable, which will cause considerable influence on measurement, thereby introducing errors. However, quite few studies considered the vibration effect. In this work, we address these issues and propose a stereophotogrammetry approach for the rotor wind tunnel test, which can make effective vibration correction and realize the full-field displacement measurements of rotor blades at arbitrary flight conditions. The main purpose is to obtain a detailed understanding of the rotor's dynamic behavior and provide accurate data for structural design and aerodynamic analysis of the helicopter rotor system.

\section{Experimental Setup}

2.1. Facility. The experiments were conducted in the $5.5 \mathrm{~m}$ $\times 4 \mathrm{~m}$ Aeroacoustic Wind Tunnel at CARDC. The wind tunnel is a low-speed, low-turbulence, single return flow-type wind tunnel with both open test section and closed test section, driven by a $12500 \mathrm{~kW}$ variable-speed electric motor. In this study, the open test section was used for the experiments, which is rectangular in a cross-sectional shape, with a width of $5.5 \mathrm{~m}$ and a height of $4 \mathrm{~m}$. By adjusting the drive 


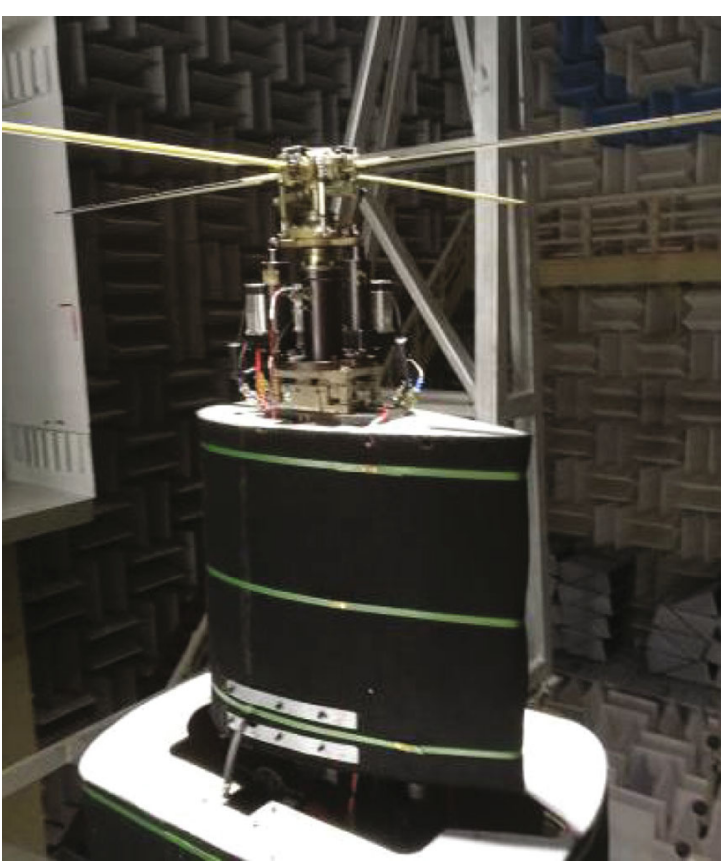

(a)

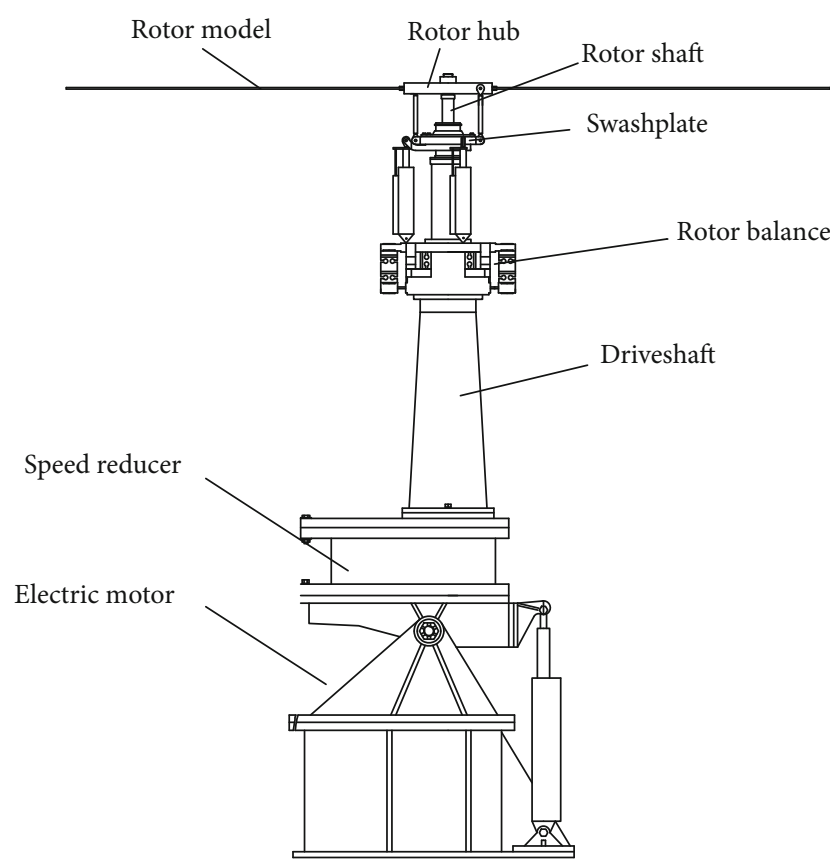

(b)

Figure 2: (a) Rotor test stand and (b) its technical drawing.

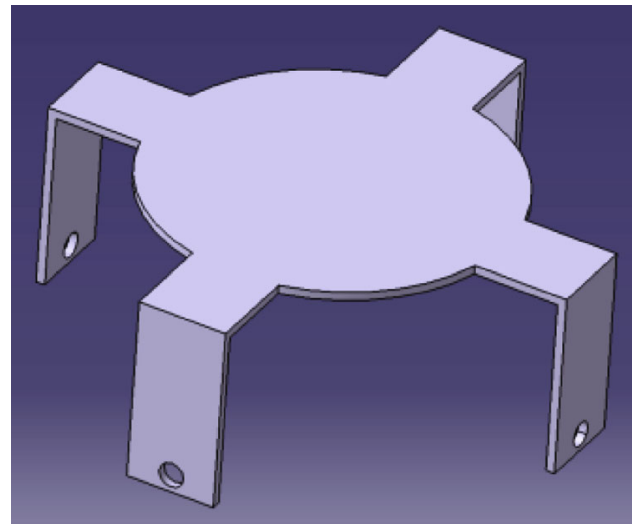

(a)

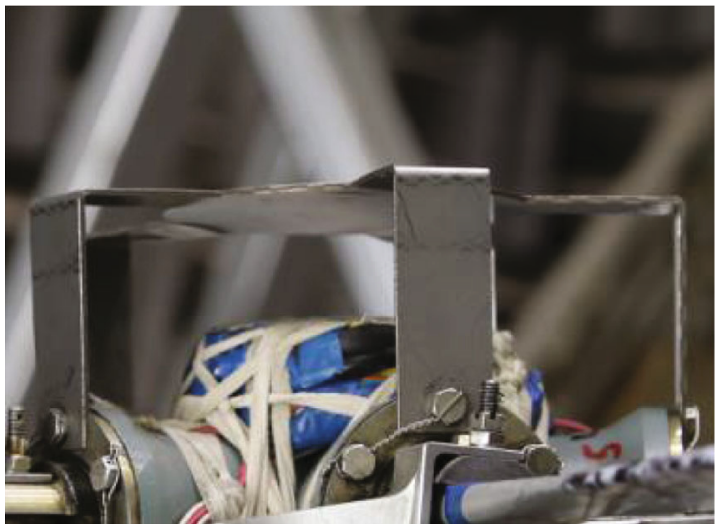

(b)

Figure 3: (a) Structure and (b) installation of the hub hat.

motor speed with a variable frequency inverter, the test section velocity can be varied between $8 \mathrm{~m} / \mathrm{s}$ and $100 \mathrm{~m} / \mathrm{s}$, and the turbulence level is below $0.2 \%$. The background noise level is below $80 \mathrm{dBA}$ at $80 \mathrm{~m} / \mathrm{s}$, and the cutoff frequency is $100 \mathrm{~Hz}$. The overall structure of the wind tunnel is shown in Figure 1.

2.2. Rotor Test Stand and Model. The rotor test stand used in the experiments is shown in Figure 2, which is driven by an electric motor with the maximum output power of $65 \mathrm{~kW}$. In order to mitigate the driveshaft wake, a fairing was installed to surround the driveshaft. The rated speed of the rotor shaft is $2072 \mathrm{rpm}$, while its control accuracy is better than $1 \%$. The range of the rotor shaft angle is from $-15^{\circ}$ to $+10^{\circ}$, and the range of the blade collective pitch angle is from $0^{\circ}$ to $+15^{\circ}$, both of which have the control accuracy better than $0.1^{\circ}$. The rotor has a rotating radius of $1 \mathrm{~m}$ and is equipped with four identical blades, which have a chord of $C=63 \mathrm{~mm}$ and a negative linear twist of $-12^{\circ}$. The configuration of the rotor hub is hingeless. To accurately track the dynamic motion of the rotor shaft, a special hat was designed and installed directly above the rotor hub, centered on the axis of the rotor shaft. Figure 3(a) shows the structure of the hub hat, which fits with the rotor hub absolutely and has a $120 \mathrm{~mm}$ diameter disk in the center. The field installation of the hub hat is shown in Figure 3(b).

In the experiments, fifty-two retroreflective targets with $20 \mathrm{~mm}$ diameter, two per radial location, uniformly spaced at $30 \mathrm{~mm}$ intervals between the blade cuff and blade tip, 


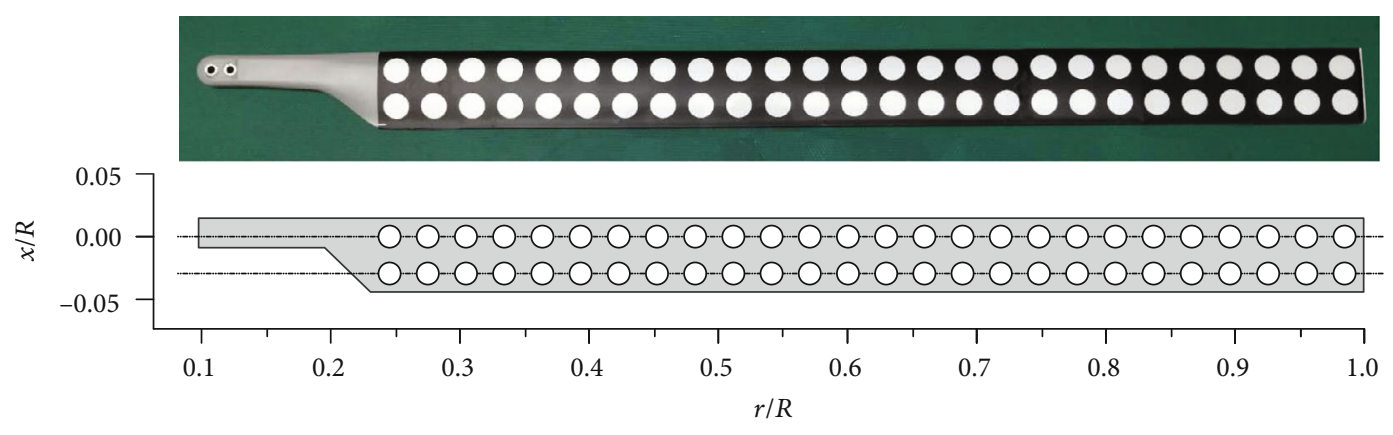

(a)
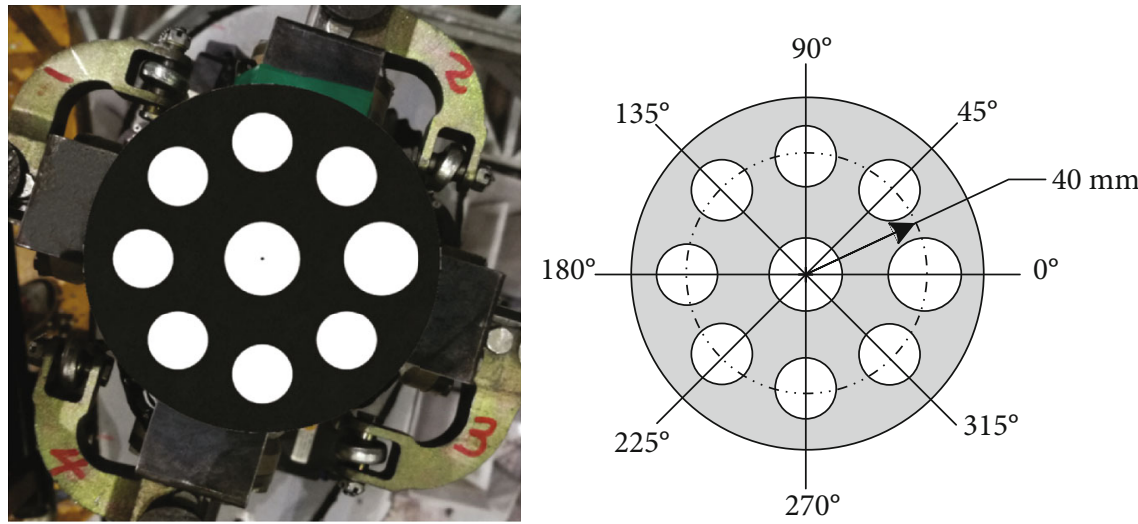

(b)

FIgURE 4: Distribution of (a) blade retroreflective targets and (b) hub retroreflective targets.

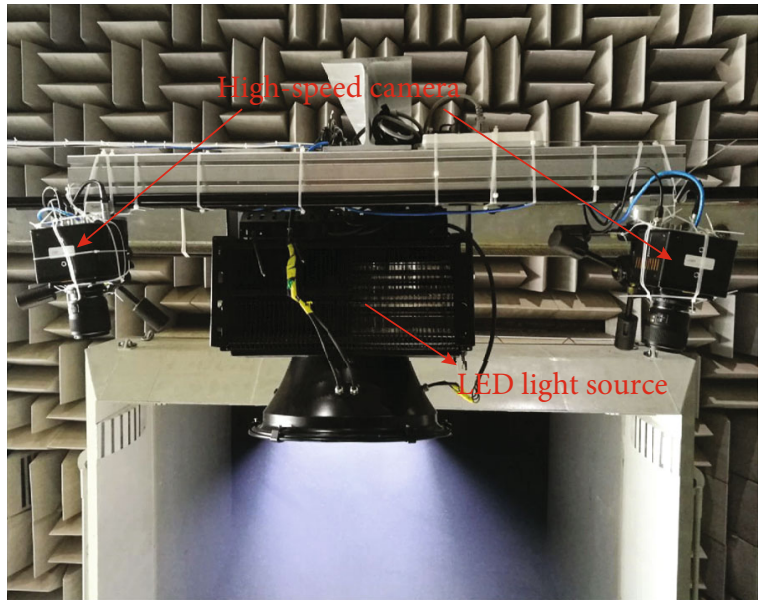

Figure 5: The imaging system.

were pasted on one of the four blades, covering the blade span from approximately $r / R=0.23$ to 0.98 . Besides, another nine retroreflective targets, two with $30 \mathrm{~mm}$ diameter and seven with $20 \mathrm{~mm}$ diameter, were also arranged on the hub hat. One of the two large targets was located in the hat center, and all the others uniformly surrounded it with the same distances of $40 \mathrm{~mm}$. Figure 4 illustrates the distribution of the retroreflective targets on the blade and the hub hat.

2.3. Imaging System. Two Photron FASTCAM Mini WX100 high-speed cameras that have the 12 bit CMOS sensors and

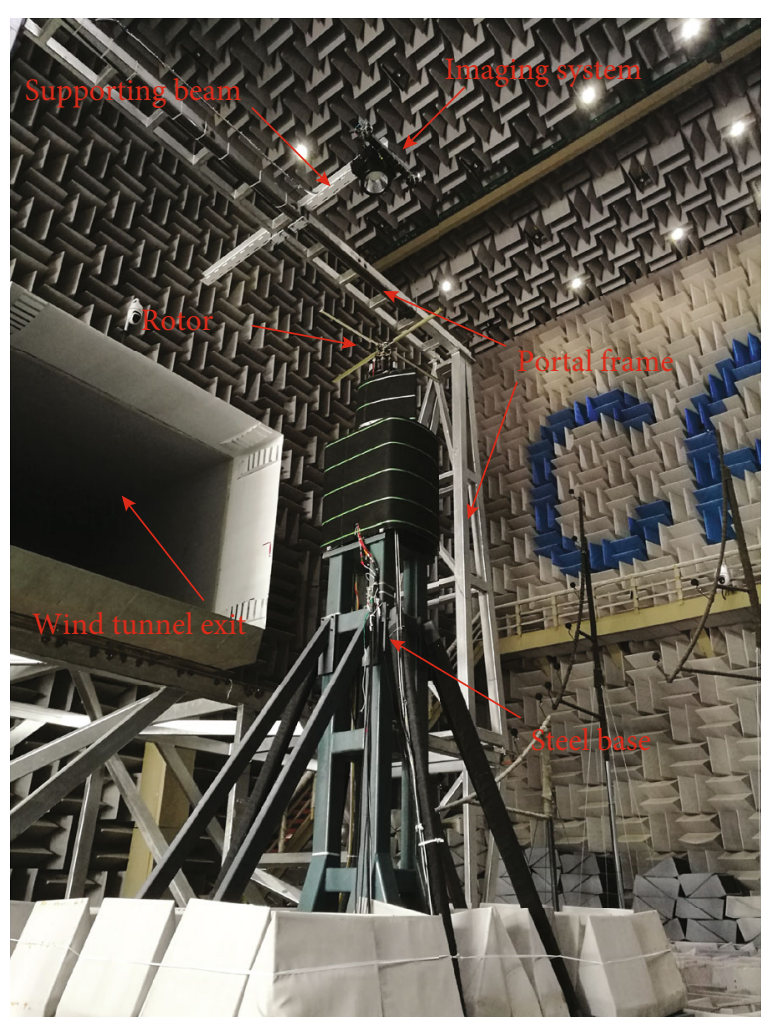

Figure 6: Overview of the experimental installation. 


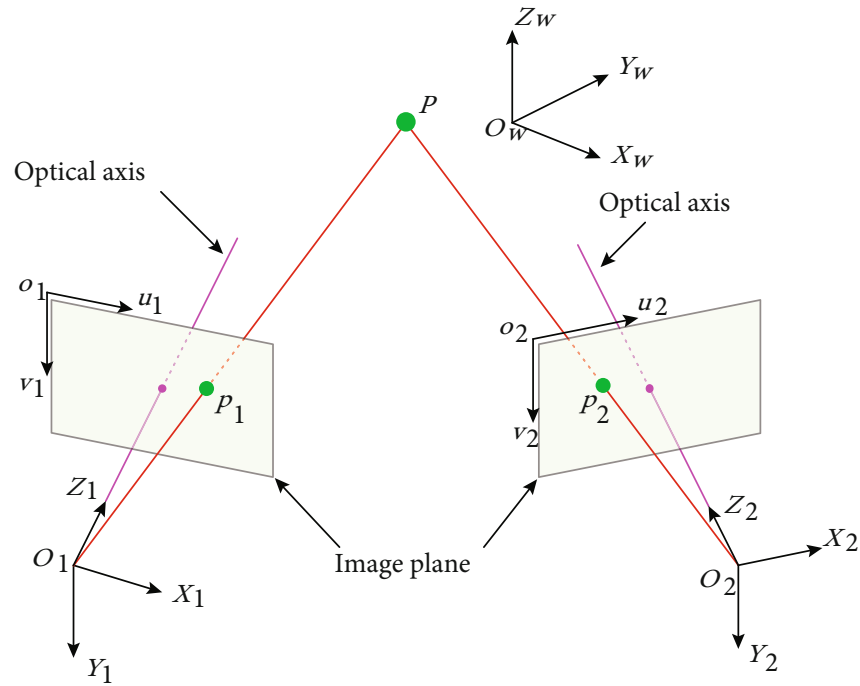

FIGURE 7: Principle of binocular stereophotogrammetry.

can provide $2048 \times 2048$-pixel resolution at $1080 \mathrm{fps}$ were used to record the rotor motion in the experiments. The minimum exposure time of both cameras is $2.7 \mu \mathrm{s}$, allowing the transient imaging of rotating rotor at high speed. To ensure that the two cameras have sufficient light in short exposure mode, a $1500 \mathrm{~W}$ LED light source was used to continuously provide high-intensity illumination. Figure 5 shows the imaging system, which was installed above the rotor. Two Nikon $35 \mathrm{~mm} \mathrm{f/1.8G} \mathrm{ED} \mathrm{lenses} \mathrm{were} \mathrm{used} \mathrm{for} \mathrm{each} \mathrm{camera}$ to cover the full range of rotor motion. According to the signals of the rotor shaft encoder at different azimuth angles, the imaging system was triggered simultaneously by the synchronous controller to acquire the transient images of rotor blades.

2.4. Installation. An overview of the experimental installation is shown in Figure 6. The rotor test stand was supported by a solid steel base, making the rotor located at the center of the wind tunnel. A huge portal frame was placed outside the nozzle outlet, and a supporting beam was fixed on its top center, extending directly over the rotor, where the imaging system was installed. The distance between the imaging system and the rotor was about $4 \mathrm{~m}$, while the distance between the rotor and the floor was about $8 \mathrm{~m}$.

2.5. Test Conditions. Hover and forward flight conditions were measured continuously throughout the experiments. For hover flight, measurements were performed at the rotor rotation speed of $N=2064 \mathrm{rpm}$, with various collective pitch angles of $\theta=0^{\circ}, 2^{\circ}, 4^{\circ}, 6^{\circ}$, and $8^{\circ}$. For forward flight, the conditions included a rotor rotation speed of $N=2064 \mathrm{rpm}$, freestream velocity of $V=34.6 \mathrm{~m} / \mathrm{s}$, advance ratio of $\mu=0.16$, thrust coefficient of $C_{\mathrm{T}}=0.013$, and varied rotor shaft angles of $\alpha=-4^{\circ},-2^{\circ}, 0^{\circ}, 2^{\circ}$, and $4^{\circ}$. In addition, the hover flight condition with $N=50 \mathrm{rpm}$ and $\theta=0^{\circ}$ was also measured, which provided a reference to calculate the blade displacements at different test conditions.

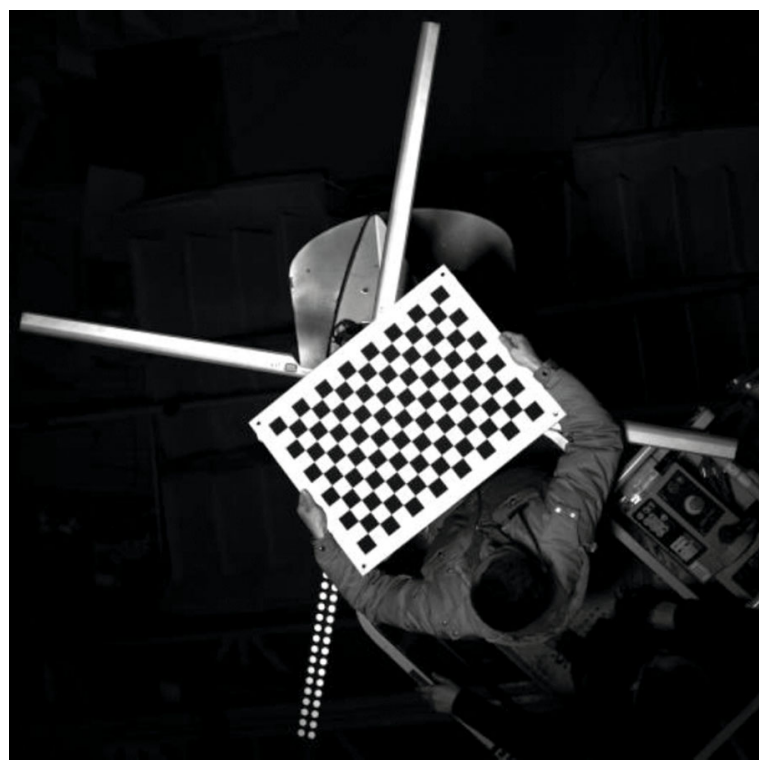

FIgURE 8: An example of the camera calibration images.

\section{Binocular Stereophotogrammetry}

3.1. Camera Calibration. The principle of binocular stereophotogrammetry is shown in Figure 7. By making measurements from the two photographic images taken by two cameras with different positions and orientations, the $3 \mathrm{D}$ coordinate of the point in the real world can be calculated. Camera calibration is used to establish the mapping function between the real-world dimensions and the camera image dimensions, which relates the $3 \mathrm{D}$ point to its $2 \mathrm{D}$ image projections. This calibration procedure is crucial, as it defines the position and orientation of the cameras with respect to the test object as well as a reference coordinate system in which all the outputs are expressed. In addition, the image distortions due to perspective projections and inherent camera lens distortions can also be corrected through the calibration. 
TABLE 1: Calibration results.

\begin{tabular}{|c|c|c|c|c|}
\hline Calibration parameters & Camera 1 & \multicolumn{3}{|c|}{ Camera 2} \\
\hline Equivalent focal length $\left(f_{x}, f_{y}\right)$ & $(3514.285,3511.958)$ & \multicolumn{3}{|c|}{$(3369.451,3368.075)$} \\
\hline Principal point $\left(x_{0}, y_{0}\right)$ & $(1057.045,981.697)$ & \multicolumn{3}{|c|}{$(1033.427,1038.164)$} \\
\hline Skewness coefficient $\gamma$ & 0 & \multicolumn{3}{|c|}{0} \\
\hline \multirow[t]{2}{*}{ Radial distortion coefficients $\left(k_{1}, k_{2}\right)$} & $(-0.109,0.204)$ & \multicolumn{3}{|c|}{$(-0.054,-0.507)$} \\
\hline & $\left(\begin{array}{lll}1 & 0 & 0\end{array}\right)$ & $(0.924$ & 0.262 & $-0.277)$ \\
\hline \multirow[t]{2}{*}{ Rotation matrix $\mathrm{R}$} & $\begin{array}{lll}0 & 1 & 0\end{array}$ & -0.239 & 0.964 & 0.111 \\
\hline & $\left(\begin{array}{lll}0 & 0 & 1\end{array}\right)$ & 0.297 & -0.036 & $0.954)$ \\
\hline Translation vector $\mathrm{T}$ & $\left(\begin{array}{lll}0 & 0 & 0\end{array}\right)^{T}$ & \multicolumn{3}{|c|}{$(-1109.584100 .05312 .965)^{T}$} \\
\hline
\end{tabular}

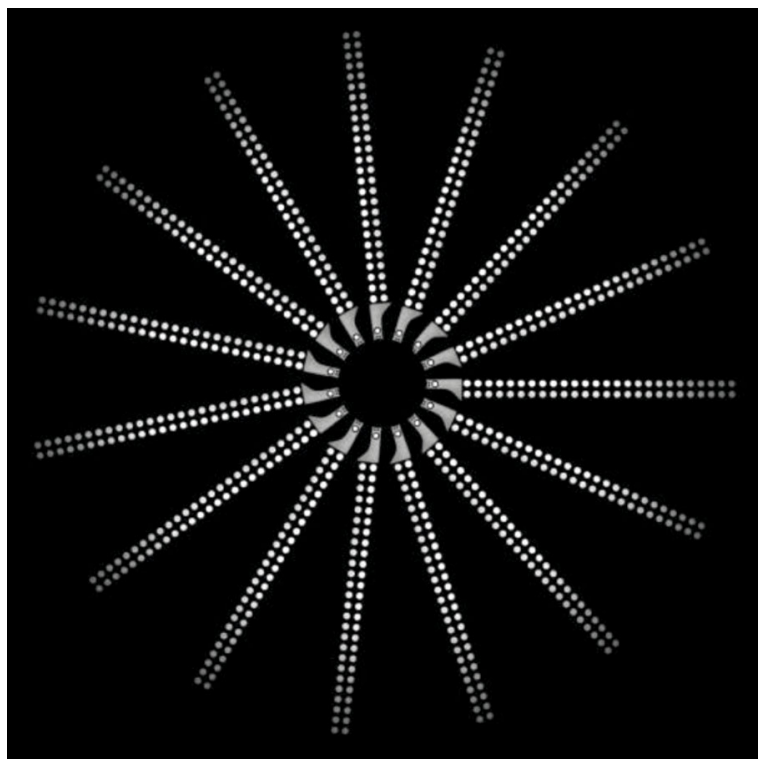

Figure 9: Unprocessed images of the measured blade at 15 azimuth locations, showing complete rotor disk at $2064 \mathrm{rpm}$.

Generally, the camera is modeled by the imaging mathematical model as follows:

$$
s\left[\begin{array}{c}
x \\
y \\
1
\end{array}\right]=\mathbf{A}[\mathbf{R T}]\left[\begin{array}{c}
X \\
Y \\
Z \\
1
\end{array}\right] \text {, }
$$

where $(x, y)$ and $(X, Y, Z)$ are the two-dimensional image coordinates and its corresponding three-dimensional coordinates; $s$ is an arbitrary scale factor; $(\mathbf{R} \mathbf{T})$, called the extrinsic parameters, is the rotation and translation which relate the world coordinate system to the camera coordinate system; and $\mathbf{A}$, called the intrinsic matrix, is given by

$$
\mathbf{A}=\left[\begin{array}{ccc}
f_{x} & \gamma & x_{0} \\
0 & f_{y} & y_{0} \\
0 & 0 & 1
\end{array}\right]
$$

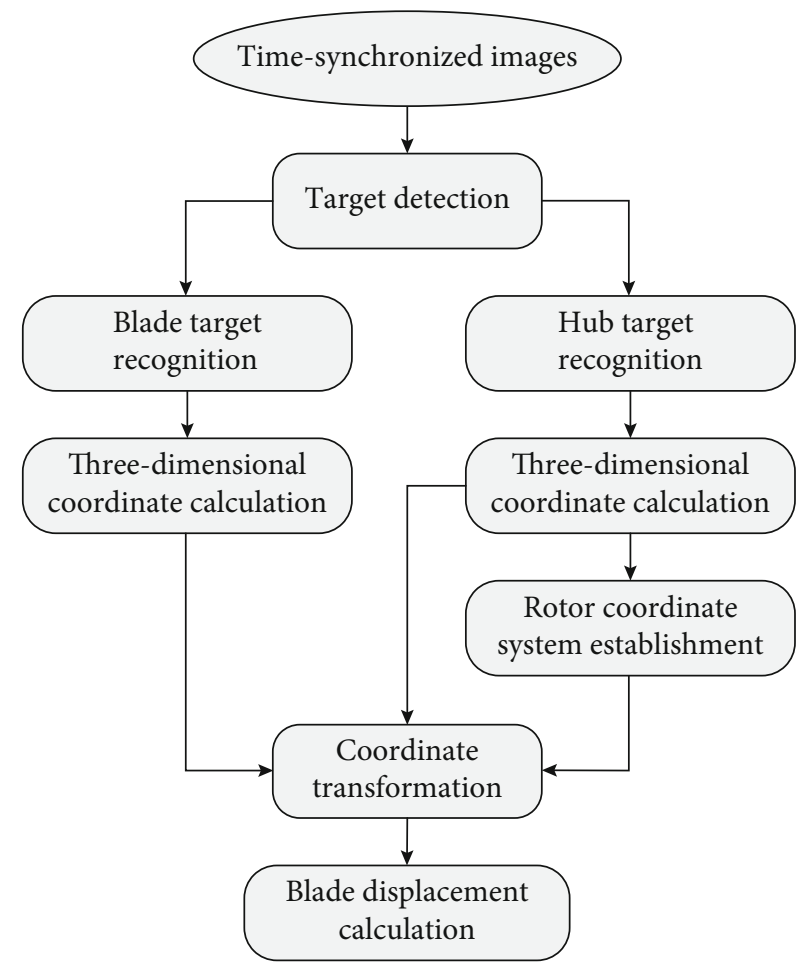

FIGURE 10: General data processing procedure.

with $\left(x_{0}, y_{0}\right)$ the coordinates of the principal point, $f_{x}$ and $f_{y}$ the equivalent focal length in image $x$ - and $y$-axes, and $\gamma$ the parameter describing the skewness of the two image axes.

Considering the radial distortion of the camera lens, its mathematical model is expressed as follows:

$$
\left\{\begin{array}{l}
\tilde{x}=x+\left(x-x_{0}\right)\left[k_{1}\left(x^{2}+y^{2}\right)+k_{2}\left(x^{2}+y^{2}\right)^{2}\right], \\
\tilde{y}=y+\left(y-y_{0}\right)\left[k_{1}\left(x^{2}+y^{2}\right)+k_{2}\left(x^{2}+y^{2}\right)^{2}\right],
\end{array}\right.
$$

where $(x, y)$ and $(\tilde{x}, \tilde{y})$ are the ideal image coordinates and its corresponding real observed image coordinates and $k_{1}$ and $k_{2}$ are the coefficients of the radial distortion.

Camera calibration is used to determine the intrinsic, extrinsic, and distortion parameters for the cameras. In this paper, Zhang's calibration method [25] was employed 


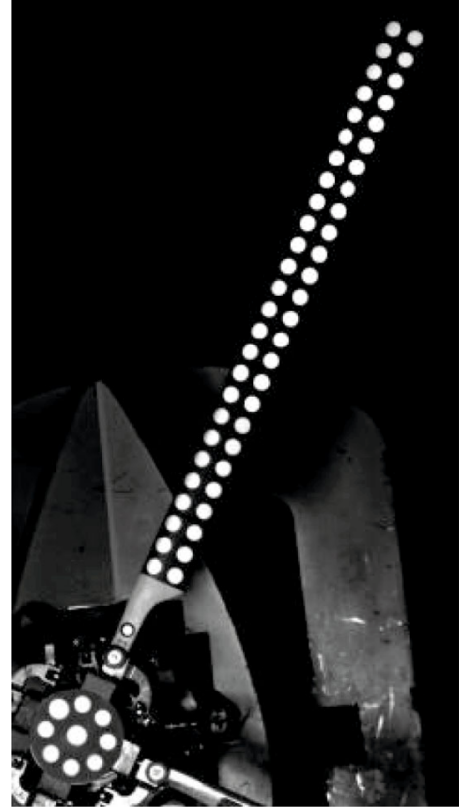

(a)

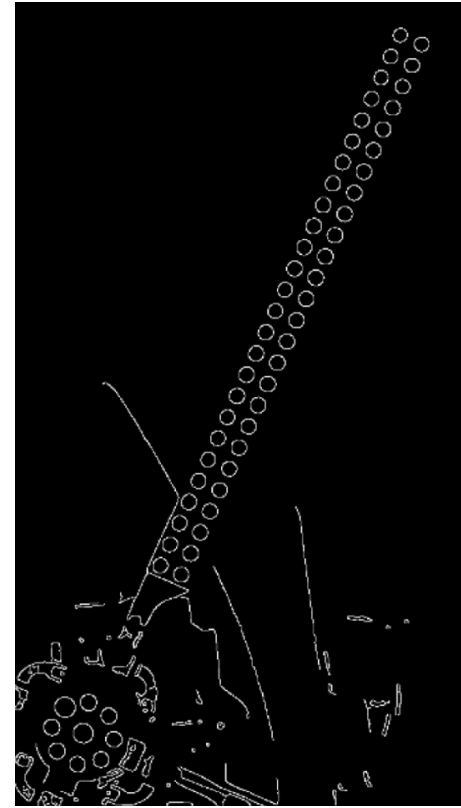

(b)

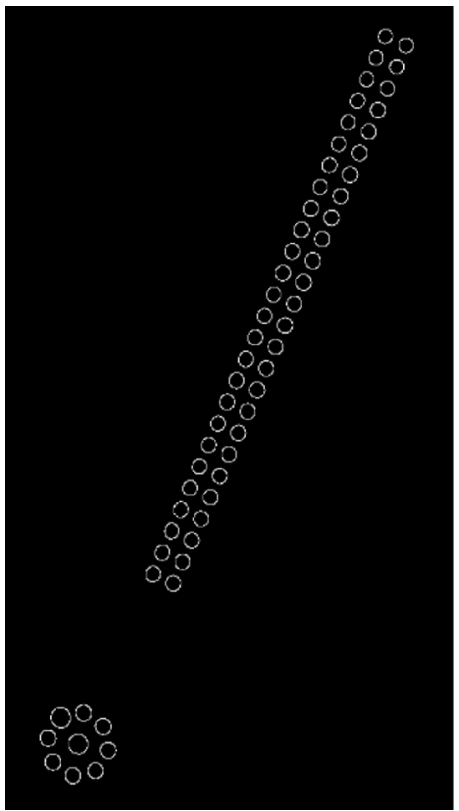

(c)

Figure 11: (a) The example image. (b) Image edge detection. (c) Target edge detection.

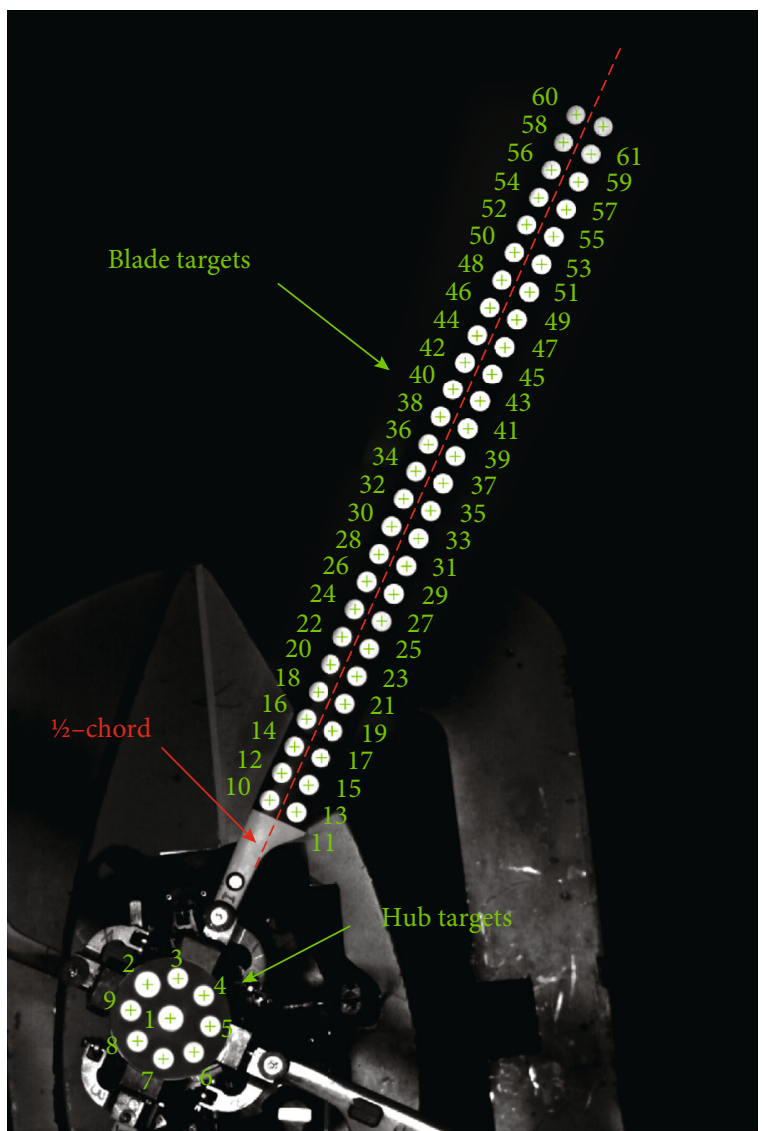

Figure 12: Numbering definition of all targets on the rotor.

to achieve the camera calibration. With a series of images of a two-dimensional calibration board at its different positions and orientations, this method can resolve the

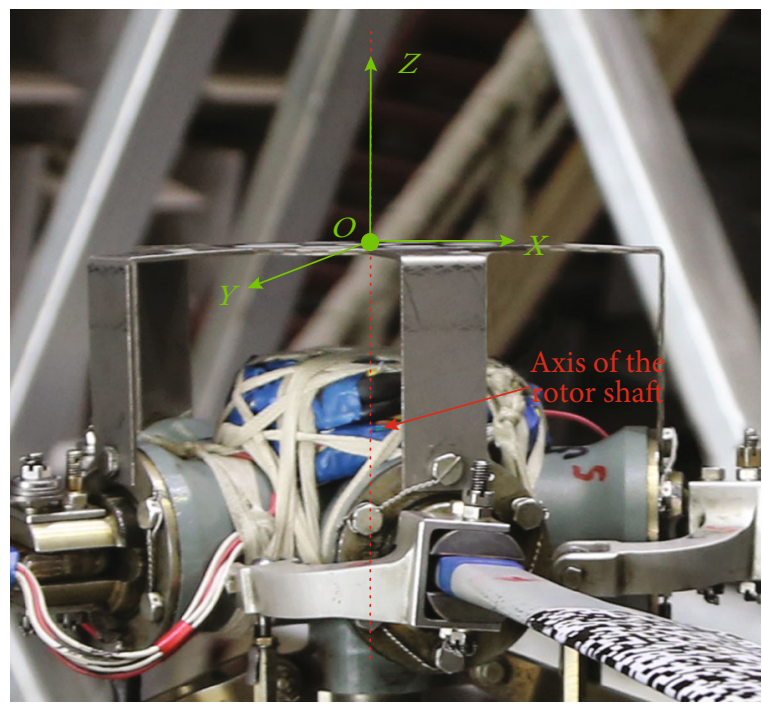

FIGURE 13: Rotor coordinate system.

intrinsic and extrinsic parameters for the cameras, while the image distortions are also corrected. So far, Zhang's calibration method has been used as a common toolbox in many image processing software. Therefore, in our experiments, the Stereo Camera Calibrator app in the MATLAB software was used to realize the two cameras' stereocalibration. During calibration, a checkerboard plate with a size of $660 \mathrm{~mm} \times 500 \mathrm{~mm}$ was used as the calibration board. It contains $15 \times 11$ black and white grids, each of which is $40 \mathrm{~mm} \times 40 \mathrm{~mm}$ in size, and obtains the machining accuracy of $\pm 0.01 \mathrm{~mm}$. To make sure that the checkerboard calibration board stayed within the two cameras' depth of field, it was placed as close to the rotor 


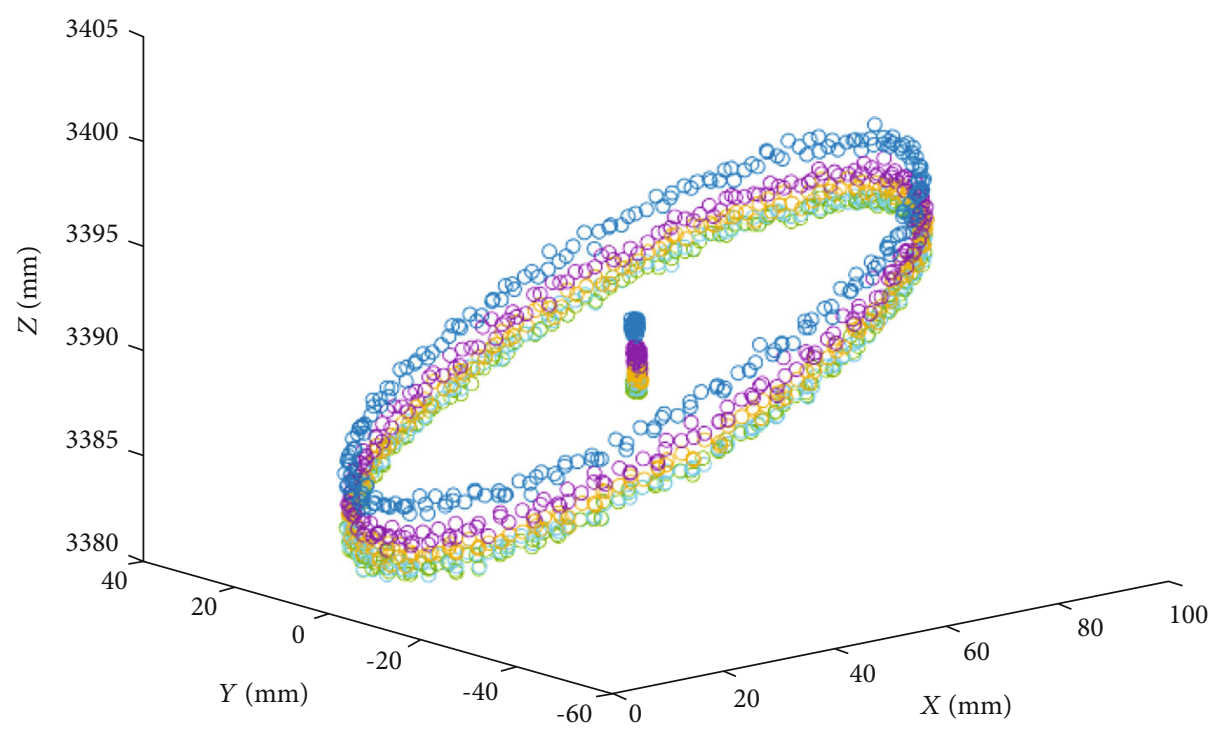
$\bigcirc 0^{\circ}$
○ $6^{\circ}$
(1) $2^{\circ}$
○ $8^{\circ}$
( $4^{\circ}$

(a)

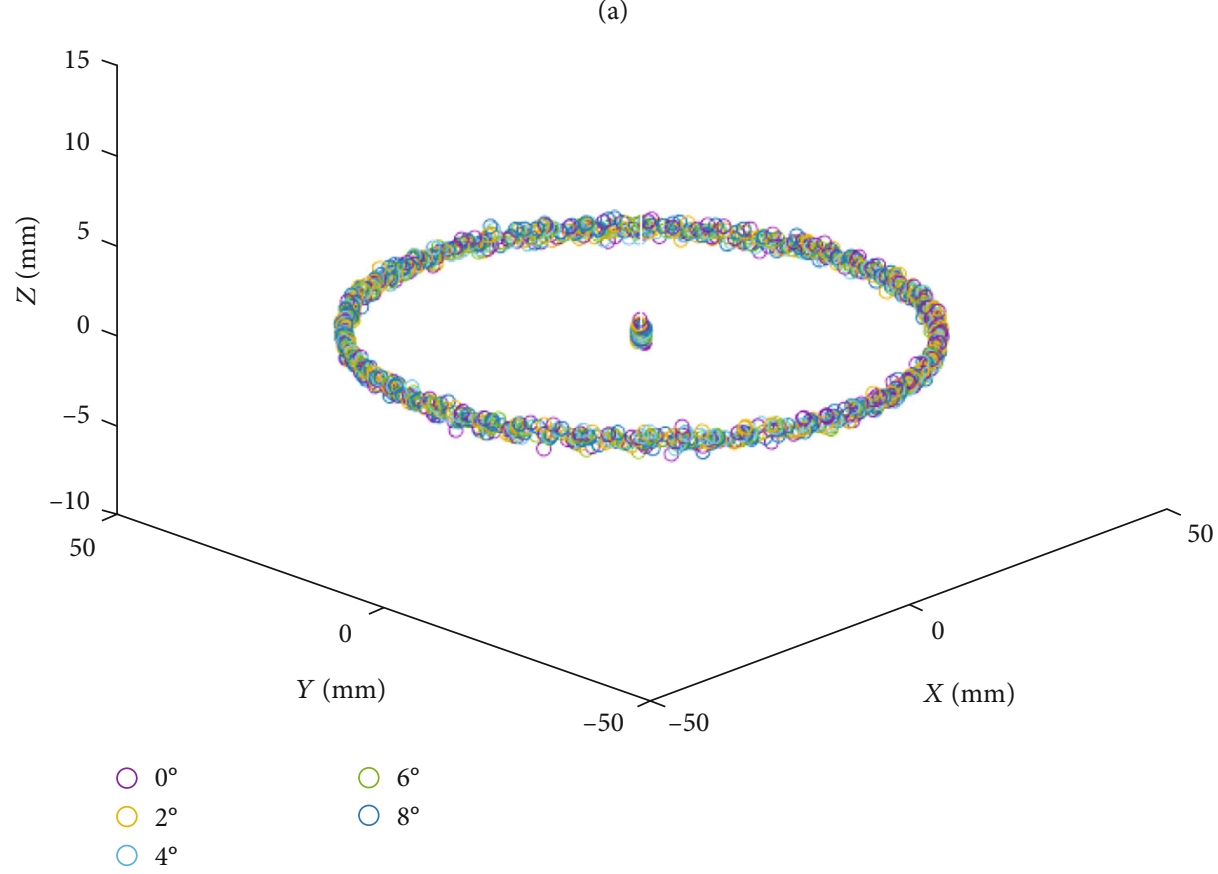
$\bigcirc 0^{\circ}$
○ $6^{\circ}$
$2^{\circ}$
$\bigcirc 8^{\circ}$

(b)

FIGURE 14: The measured positions of the hub targets in (a) the camera coordinate system and (b) the rotor coordinate system.

plane as possible. A total of 30 pairs of images were collected for calibration. Figure 8 shows an example of the calibration images, and Table 1 shows the calibration results.

3.2. Data Acquisition. Time-synchronized digital images from the two high-speed cameras were captured at the resolution of $2048 \times 2048$ pixels. Since the two cameras were installed directly above the rotor, the acquired images could cover the full range of blade motion. During image acquisition, the LED light source continuously provided high-intensity illumination, while the two cameras were synchronized to trigger with respect to the desired blade azimuth location, which was set in the increments of $12^{\circ}$ based on the signals of the rotor shaft encoder. For each test condition, the acquired image set consists of 90 revolutions of images per rotor azimuth, measuring the specified blade at 30 azimuth locations over the full $360^{\circ}$ of rotation. Figure 9 shows the unprocessed images of the measured blade at $2064 \mathrm{rpm}$ acquired by one of the two cameras at 15 per revolution, overlaid on each other to illustrate the complete rotor disk. 


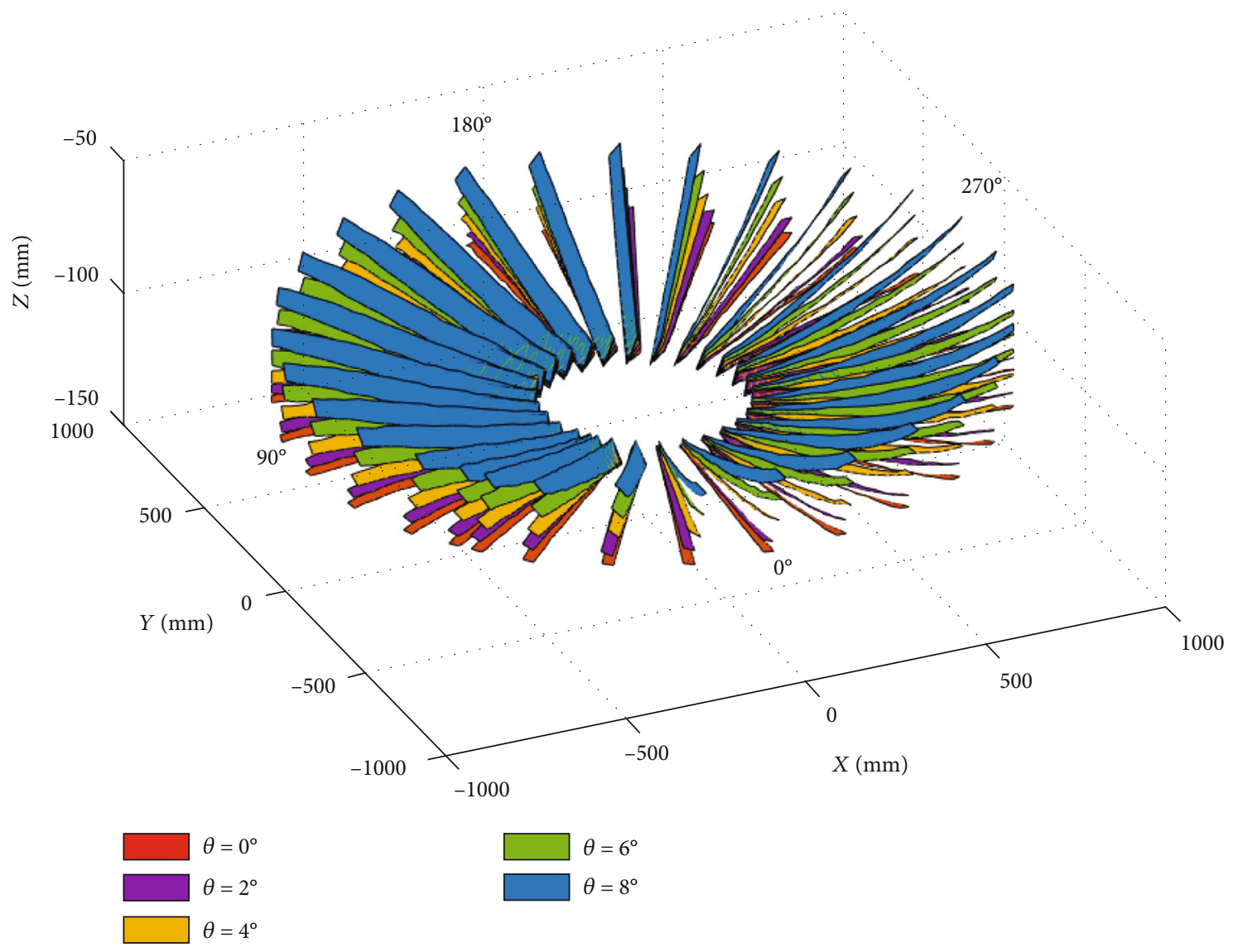

FiguRE 15: 3D reconstruction results of the measured rotor blade over its full rotating range at five different collective pitch angles in hover flight.

3.3. Data Processing. The data processing procedure is shown in Figure 10. The first step was to calculate the central locations of all targets on the rotor blade and hub hat for each image set. To this end, Canny edge detector was used to extract the image edges. With geometric constraints, such as shape and perimeter, the target edges could be retained well, while other ones were eliminated, as shown in Figure 11. To obtain more accurate target edges, Zernike orthogonal moments [26] were employed to achieve subpixel results further. With least-squares ellipse fitting on the subpixel edges of each target, their subpixel center coordinates were obtained, thus achieving accurate target locations.

Due to the same shape of the targets and the movement of the rotor about the image plane, target recognition is easy to get confused. However, thanks to the regular arrangement of the targets on the rotor blade and hub hat, they can be effectively distinguished according to their sizes and positions with respect to the rotor. The numbering rule of all targets on the rotor was defined in advance, which is illustrated in Figure 12. After that, target recognition for all image sets was fully automated. Since the hub targets and blade targets are located in different image regions, their recognition could be independent from each other. For the hub targets, the central target was identified with its size and position relative to the others first. Then, the other targets around it were distinguished clockwise starting from the large one. For the blade targets, the blade 1/2-chord served as the boundary, and their distances and orientations with respect to the hub central target were utilized to identify them effectively. After all targets were recognized correctly, the corresponding targets in the timesynchronized images from the two cameras could be matched exactly, and their 3D coordinates in the camera coordinate system were calculated based on binocular stereoprinciple.

Since the hub hat is located directly above the rotor hub and centered on the axis of the rotor shaft, it can accurately track the dynamic motion of the rotor shaft. For each image set, based on the position of the central target and the plane fitted by all the hub targets using least squares, the instantaneous location and orientation of the rotor shaft relative to vertical in the camera coordinate system were measured. Therefore, 3D coordinates of instantaneously measured targets on the blade could be transformed from the camera coordinate system to the rotor coordinate system, which provides a basis for more accurately estimating and comparing the location of the blade displacement relative to the rotor shaft at different 


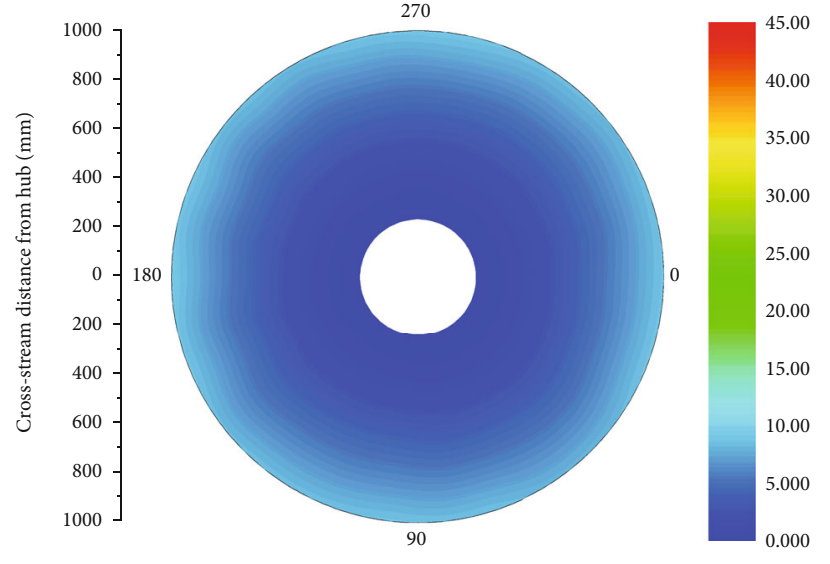

$1000 \quad 800 \quad 600 \quad 400 \quad 200 \quad 0 \quad 200 \quad 400 \quad 600 \quad 800 \quad 1000$ Streamwise distance from hub $(\mathrm{mm})$

(a)

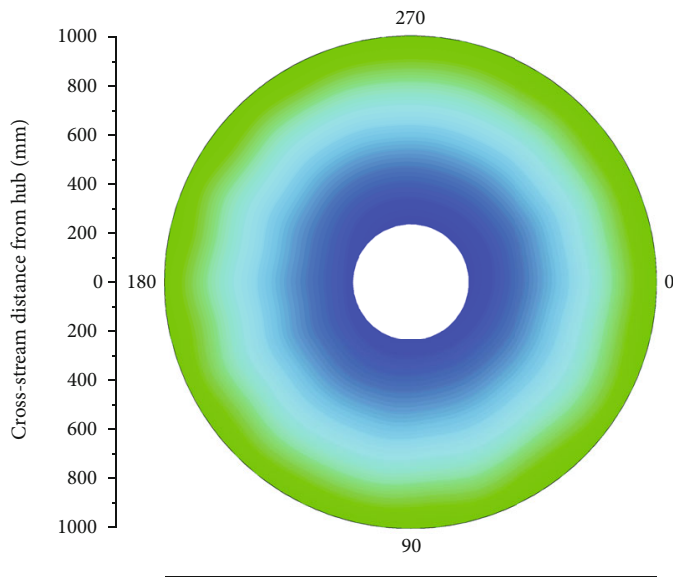

$\begin{array}{lllllllllll}1000 & 800 & 600 & 400 & 200 & 0 & 200 & 400 & 600 & 800 & 1000\end{array}$ Streamwise distance from hub $(\mathrm{mm})$

(c)

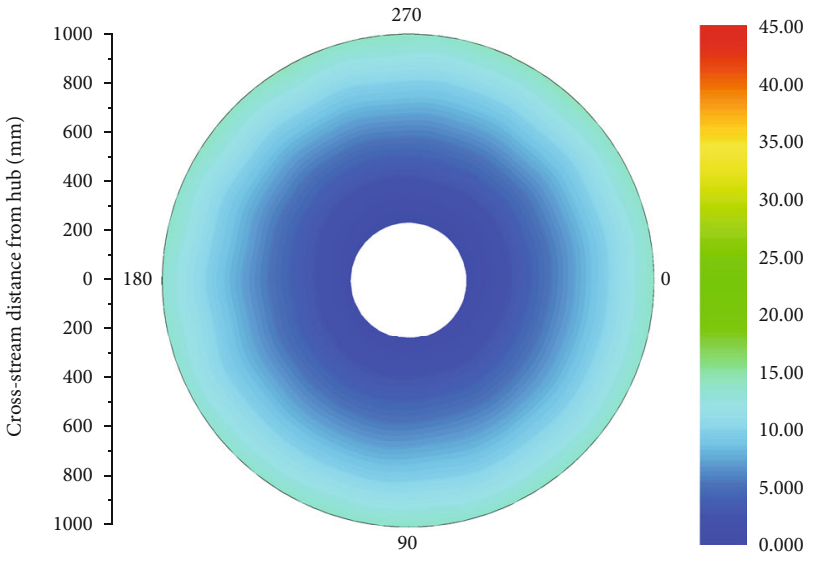

$\begin{array}{lllllllllll}1000 & 800 & 600 & 400 & 200 & 0 & 200 & 400 & 600 & 800 & 1000\end{array}$ Streamwise distance from hub $(\mathrm{mm})$

(b)

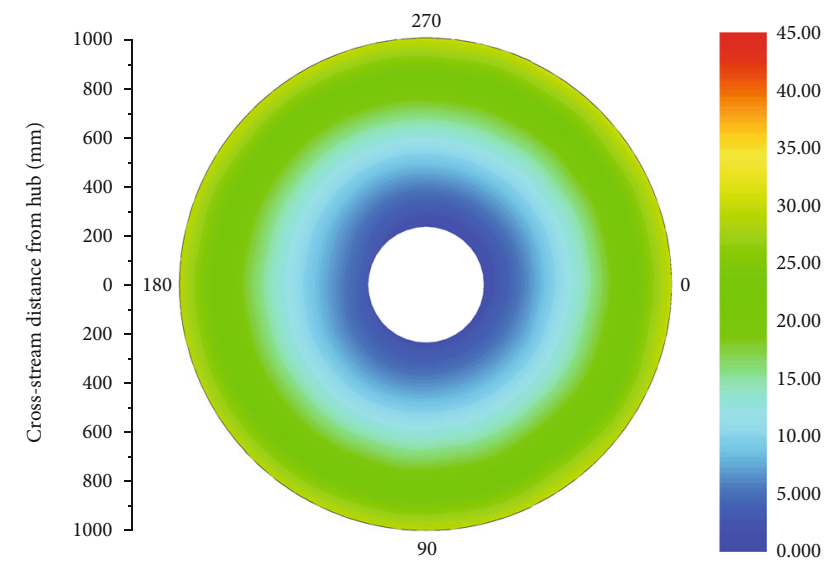

$\begin{array}{lllllllllll}1000 & 800 & 600 & 400 & 200 & 0 & 200 & 400 & 600 & 800 & 1000\end{array}$ Streamwise distance from hub $(\mathrm{mm})$

(d)

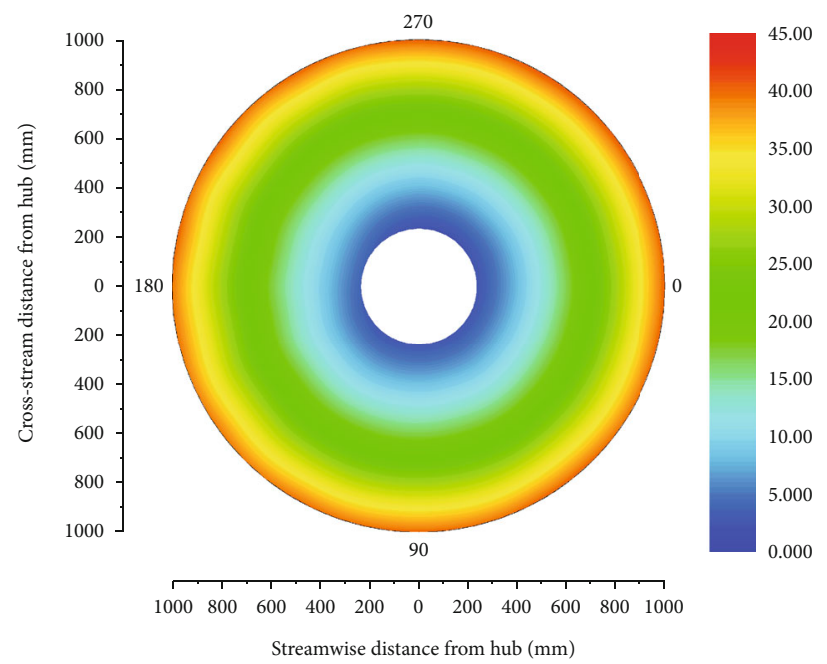

(e)

Figure 16: Blade displacements along the quarter-chord at five different collective pitch angles in hover flight: (a) $\theta=0^{\circ}$; (b) $\theta=2^{\circ}$; (c) $\theta=4^{\circ}$; (d) $\theta=6^{\circ}$; (e) $\theta=8^{\circ}$. 


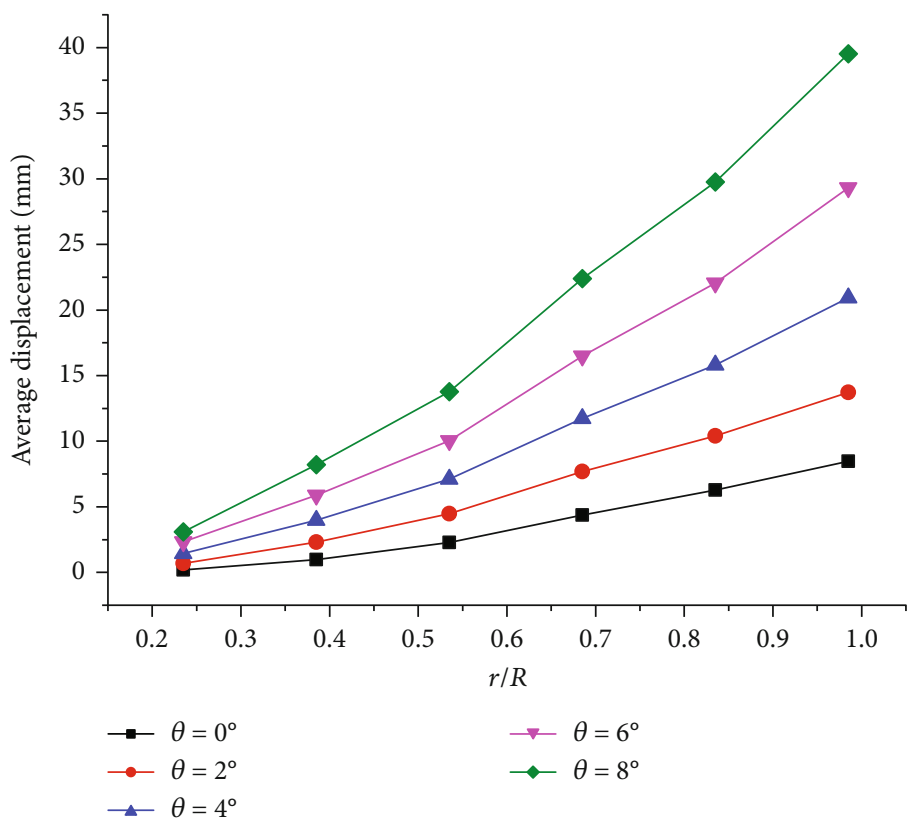

(a)

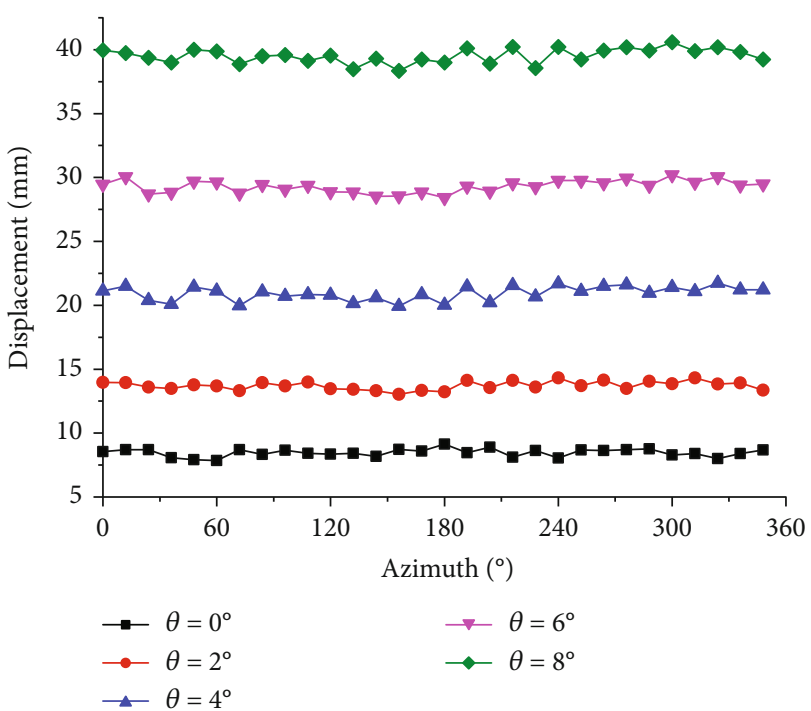

(b)

FIGURE 17: (a) Comparison of average displacements at six different radial locations. (b) Blade tip displacements at five different collective pitch angles in hover flight.

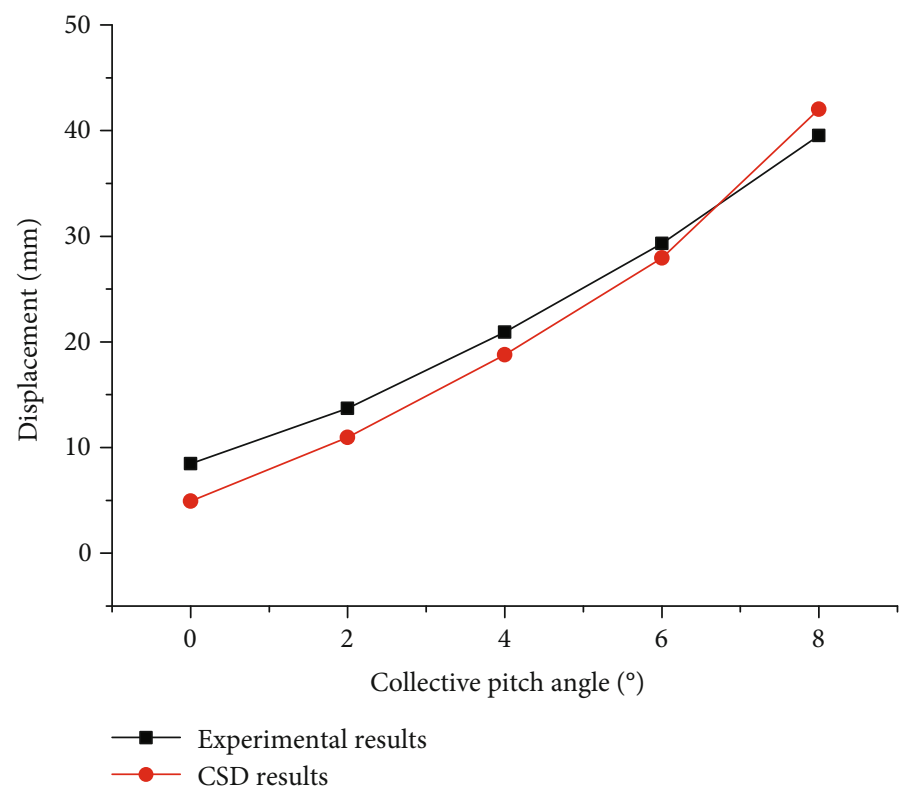

FIGURE 18: Comparison of the average blade tip displacements between experimental and CSD results.

test conditions. Figure 13 illustrates the rotor coordinate system established on the hub hat.

Another benefit of coordinate transformation is that it can correct the location deviations of the blade caused by the vibration of the measuring system or the rotor. Figure 14(a) shows the measured positions of the hub targets in the camera coordinate system at five different pitch angles with one revolution under hover flight conditions. As can be seen, there are significant deviations between the hub hat planes at different test conditions, which are supposed to be overlapped together. After coordinate transformation, these deviations are corrected effectively, as shown in Figure 14(b).

\section{Results and Discussion}

4.1. Hover Flight. By connecting the instantaneously measured 3D coordinates of adjacent blade targets using triangulated surfaces, $3 \mathrm{D}$ reconstruction of the rotor blade could be 


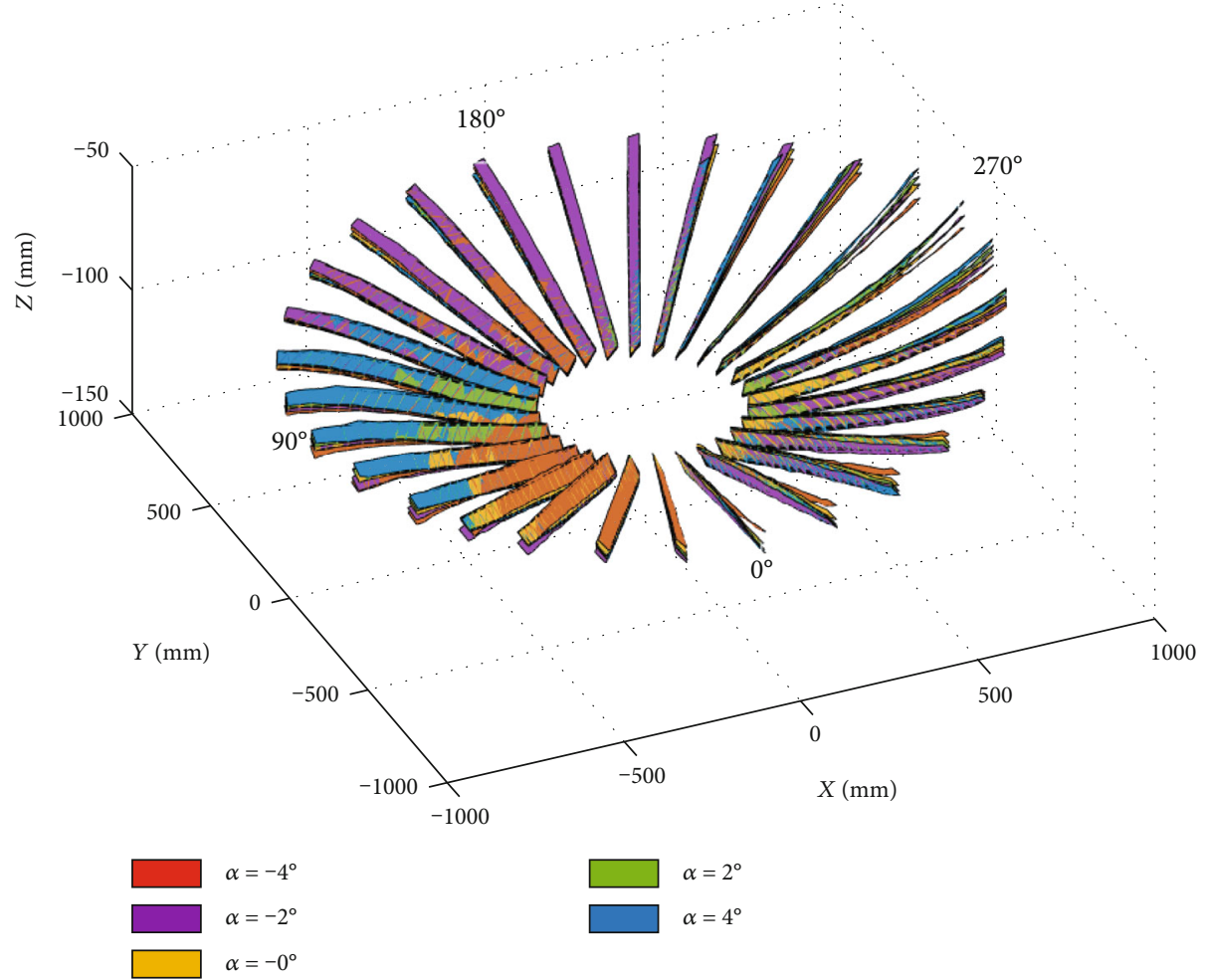

(a)

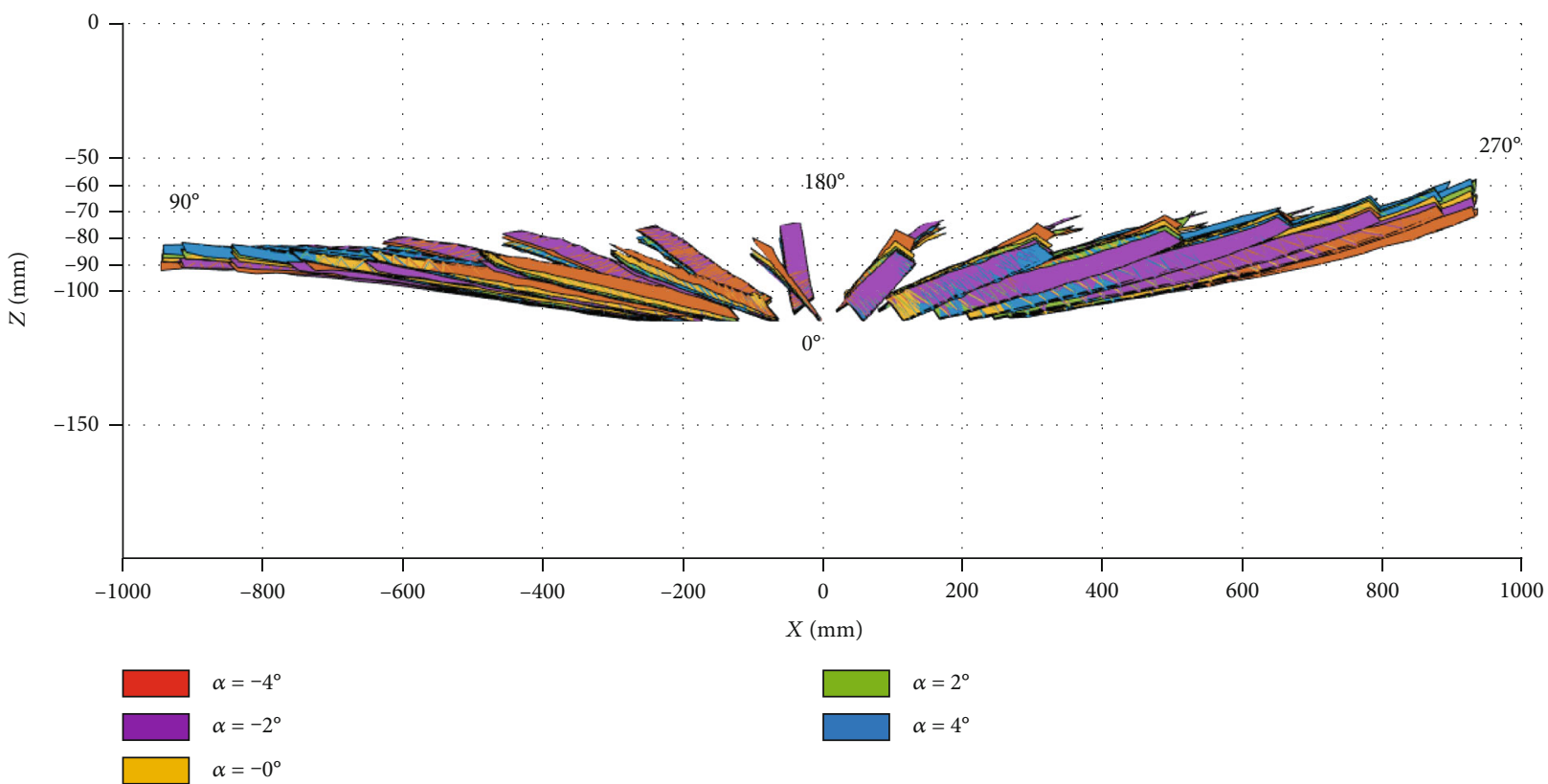

(b)

Figure 19: Continued. 


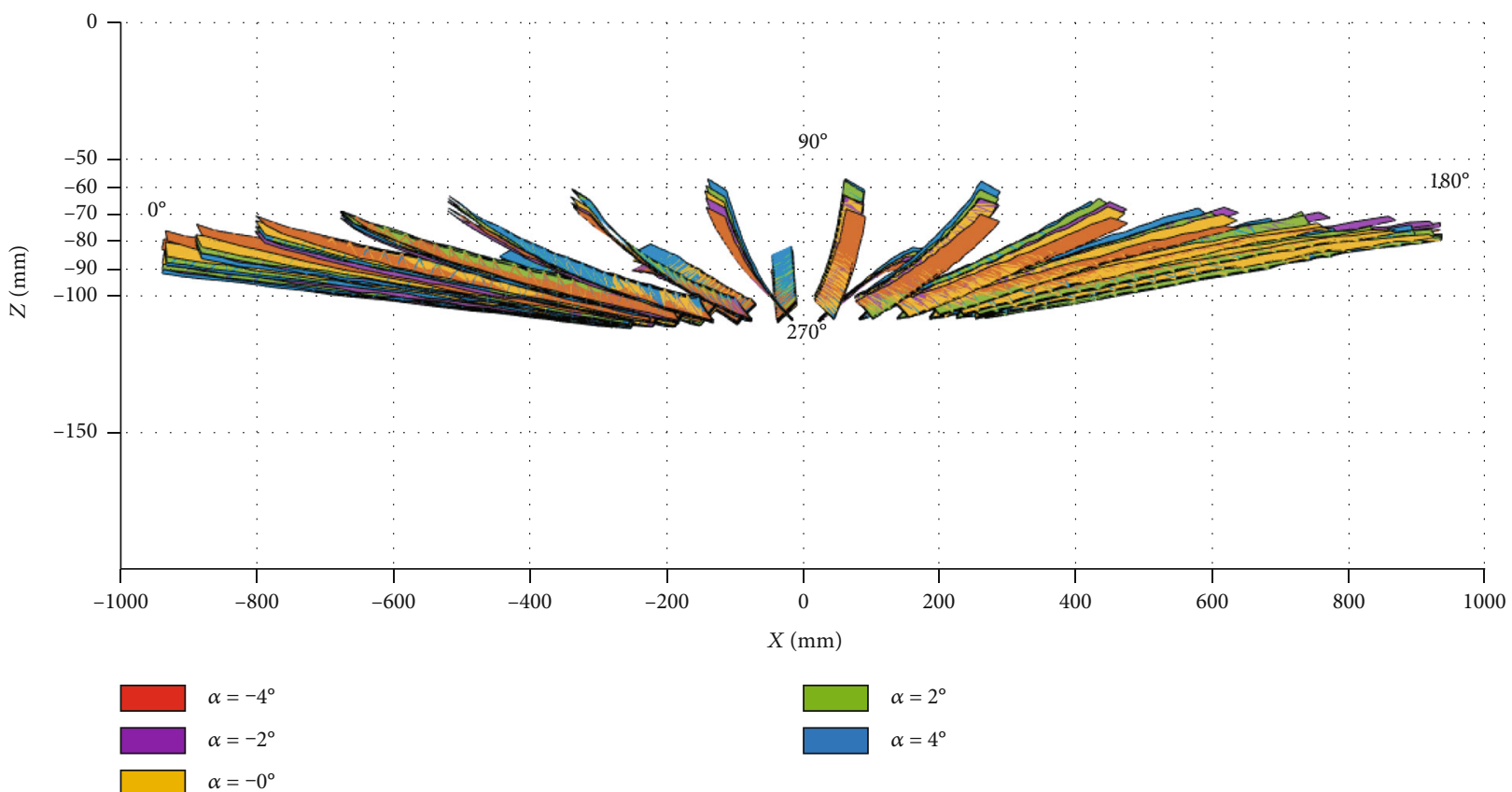

(c)

FiguRE 19: $3 \mathrm{D}$ reconstruction results of the measured rotor blade over its full rotating range at five different rotor shaft angles in forward flight: (a) top view; (b) side view along the $y$-axis; (c) side view along the $x$-axis.

achieved, which was used to analyze the dynamic motion of the rotor blade qualitatively. Figure 15 shows the $3 \mathrm{D}$ reconstruction results of the measured rotor blade over its full rotating range in hover flight, including the test conditions of $N=2064 \mathrm{rpm}$ and $\theta=0^{\circ}, 2^{\circ}, 4^{\circ}, 6^{\circ}$, and $8^{\circ}$. As can be seen, the reconstruction results were consistent with the rotor dynamics. With the increase of collective pitch angle, the lift of the rotor increased, and the blade became to be subjected to greater aerodynamic loads, thus leading it to rise gradually. For the blade root, the rise was slight. For the blade tip, however, since it suffered from the strongest aerodynamic loading, notable displacements could be observed.

To have detailed understanding of the rotor motion, the blade displacements along the quarter-chord over the entire rotor disk were calculated, shown in Figure 16. As can be seen, for each condition, the blade experienced an obvious flapping displacement at all azimuths, increasing along the radial direction, and the maximum displacements always occurred at the blade tip. The larger the collective pitch angle, the greater the displacements, which matched the $3 \mathrm{D}$ reconstruction results well. In addition, all of the displacement contour plots were nearly concentric circles, indicating the steady rotation of the blade, which is consistent with the dynamic characteristic of the rotor in hover flight.

To further compare the results quantitatively, the average displacements were extracted at six different radial locations: $r / R=0.23,0.38,0.53,0.68,0.83$, and 0.98 , shown in Figure $17(\mathrm{a})$. As the collective pitch angle increased, the blade root got quite little displacement changes, while the blade tip obtained the most significant increments. The larger the collective pitch angle, the faster the blade displacements increased along the radial direction of the blade. Moreover, the growth of blade displacements became more nonlinear as the collective pitch angle changed, indicating that the blade suffered from greater elastic deformations. The detailed displacements of the blade tip are shown in Figure 17(b). It can be seen that the blade maintained excellent stability for all test conditions. The standard deviations of the displacements were $0.30 \mathrm{~mm}, 0.33 \mathrm{~mm}, 0.55 \mathrm{~mm}, 0.49 \mathrm{~mm}$, and $0.57 \mathrm{~mm}$, corresponding to the test conditions of $\theta=0^{\circ}, 2^{\circ}$, $4^{\circ}, 6^{\circ}$, and $8^{\circ}$.

Furthermore, comparisons of the average blade tip displacements between experimental and CSD results are shown in Figure 18. The CSD results, which were calculated with the CAMRAD software, presented a slightly larger ascending rate compared to the experimental results. For small collective pitch angles, the measured displacements were greater than the CSD results. However, with the increase of the collective pitch angle, the two results became consistent. This difference may come from the differences in the structure parameters between the simulation model and the actual blade. Overall, the two results agree with each other well.

4.2. Forward Flight. Figure 19 shows the 3D reconstruction results of the measured rotor blade over its full rotating range in forward flight, encompassing a range of test conditions that include $N=2064 \mathrm{rpm}, V=34.6 \mathrm{~m} / \mathrm{s}, \mu=0.16, C_{\mathrm{T}}=$ 0.013 , and $\alpha=-4^{\circ},-2^{\circ}, 0^{\circ}, 2^{\circ}$, and $4^{\circ}$. Due to cyclic pitch control, the collective pitch angle of the blade, together with its displacements, exhibited a complex dynamic change, which was quite different from the results in hover flight. For each condition, the maximum blade tip displacements always appeared near $\psi=270^{\circ}$, where it was expected to have the greatest collective pitch angle during forward flight. In addition, it can be observed that the blade with different rotor shaft angles crossed each other at some azimuths, most 


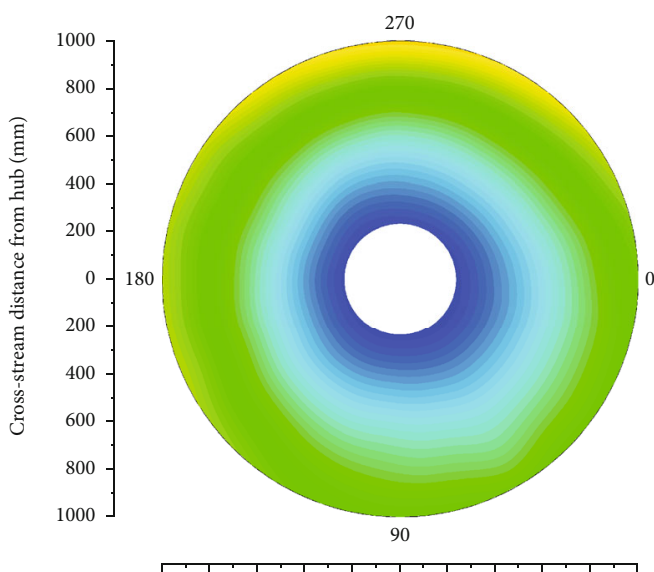

$\begin{array}{lllllllllll}1000 & 800 & 600 & 400 & 200 & 0 & 200 & 400 & 600 & 800 & 1000\end{array}$ Streamwise distance from hub $(\mathrm{mm})$

(a)

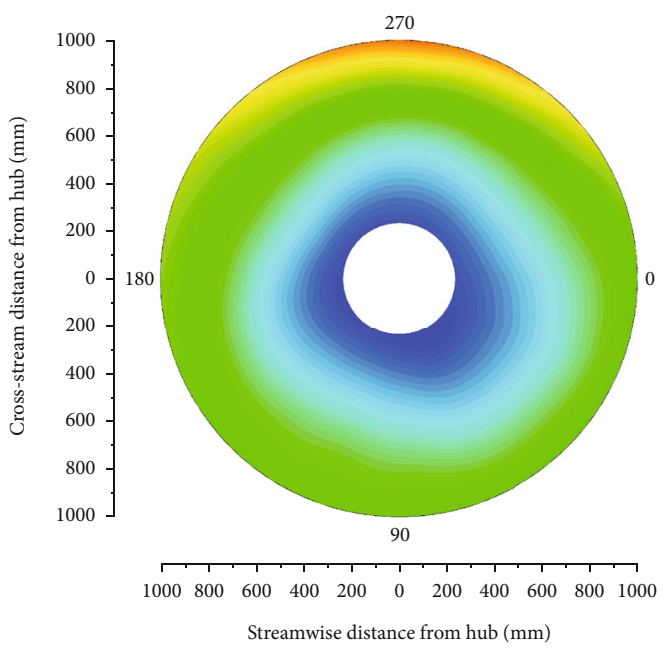

(c)

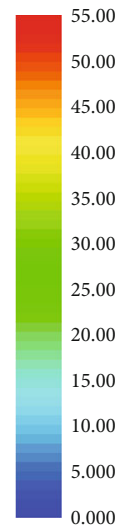

0.000
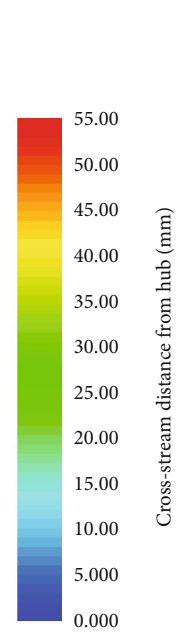
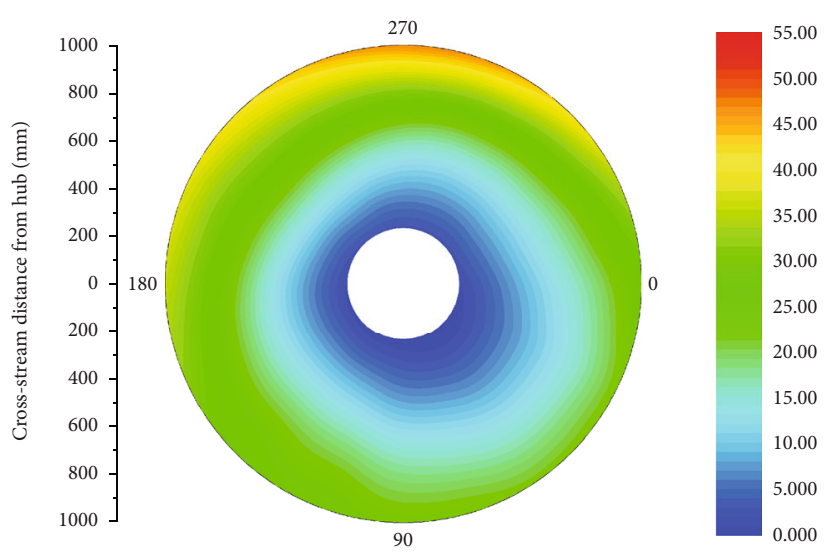

$\begin{array}{lllllllllll}1000 & 800 & 600 & 400 & 200 & 0 & 200 & 400 & 600 & 800 & 1000\end{array}$ Streamwise distance from hub $(\mathrm{mm})$

(b)

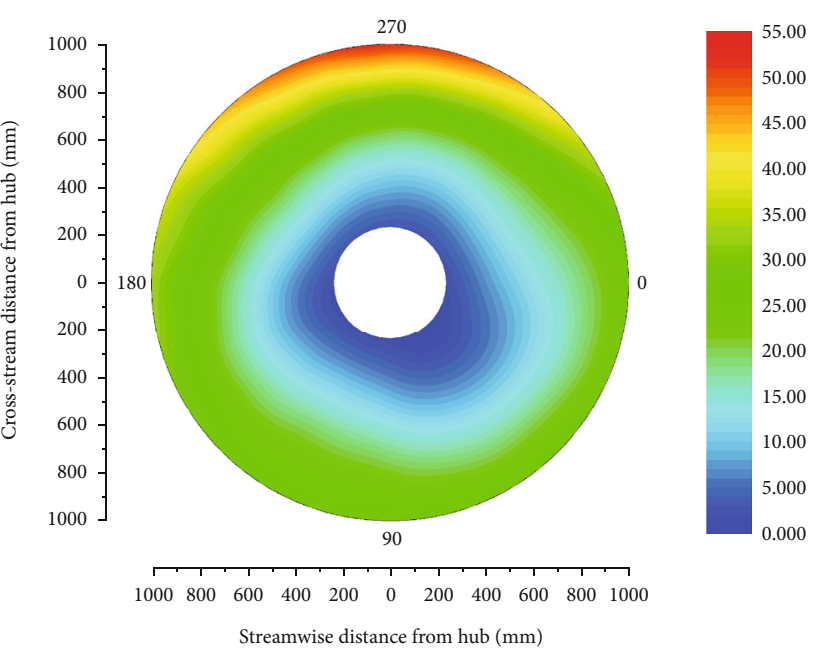

(d)

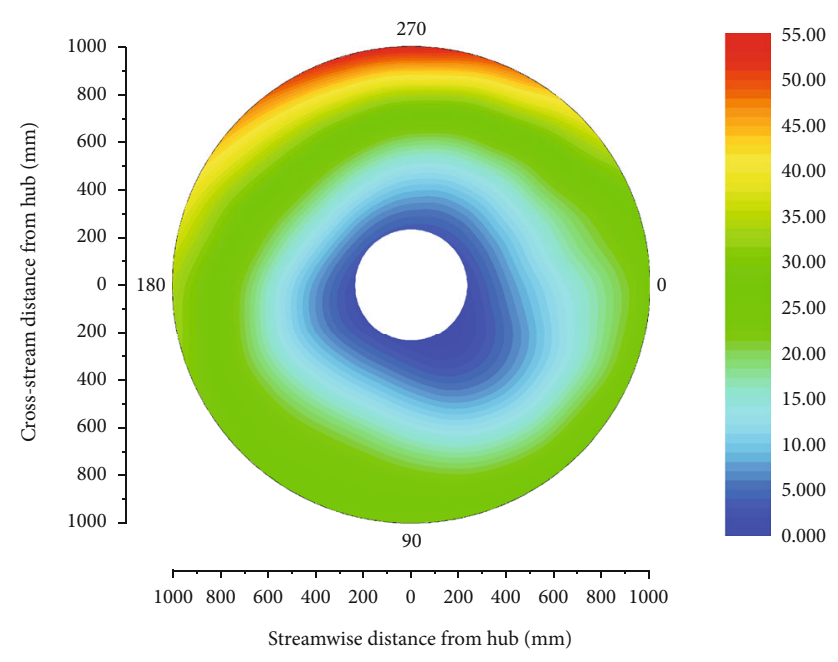

(e)

FigURE 20: Blade displacements along the quarter-chord at five different rotor shaft angles in forward flight: (a) $\alpha=-4^{\circ}$; (b) $\alpha=-2^{\circ}$; (c) $\alpha=0^{\circ}$; (d) $\alpha=2^{\circ}$; (e) $\alpha=4^{\circ}$. 


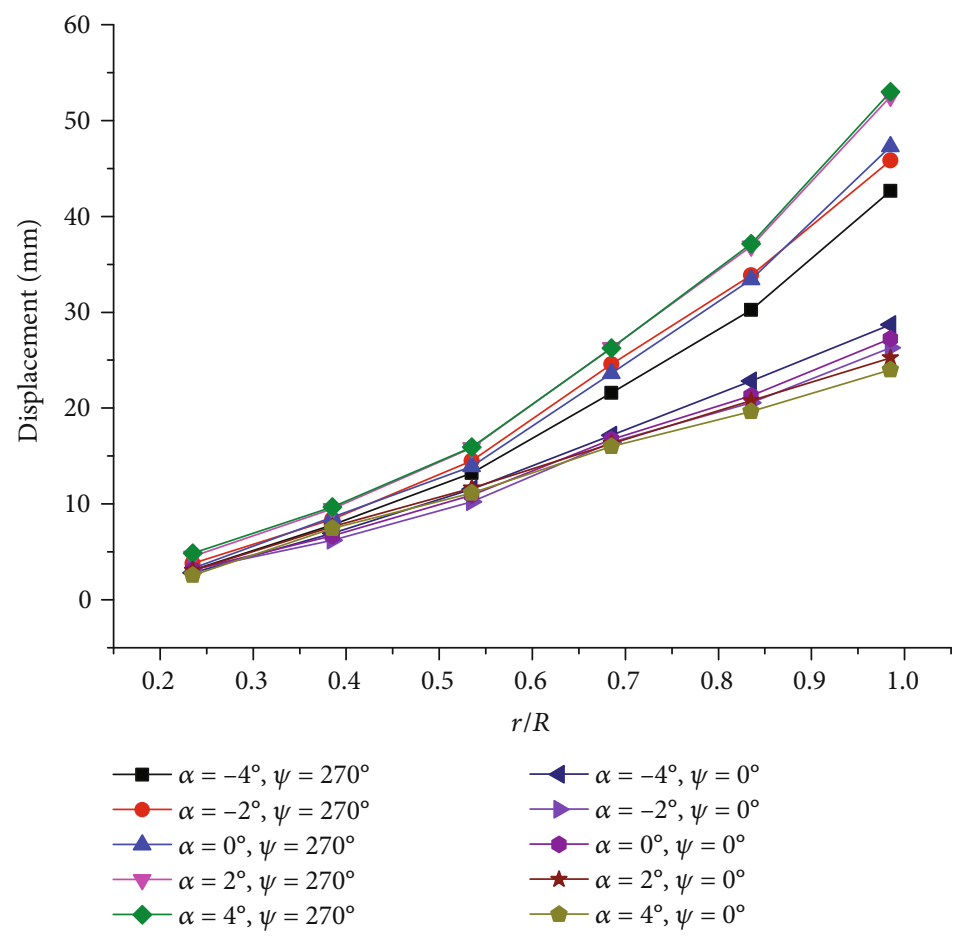

Figure 21: Blade displacements at $\psi=0^{\circ}$ and $270^{\circ}$ with six different radial locations.

notably at the blade tip, indicating that the blade suffered from different deformations at each test condition.

The detailed blade displacements along the quarterchord over the entire rotor disk are shown in Figure 20. For the locations close to the blade root, the displacement changes over the rotating revolution were relatively small. As the blade locations increased along the radial direction, the displacement changes became more obvious, peaking at the blade tip. As can be seen, the maximum blade tip displacements of all test conditions appeared near $\psi=270^{\circ}$, matching the $3 \mathrm{D}$ reconstruction results well. Besides, the blade also suffered from different deformations at each azimuth location due to different aerodynamic effects. Figure 21 shows the blade displacements at $\psi=0^{\circ}$ and $270^{\circ}$ with six different radial locations: $r / R=0.23,0.38,0.53$, $0.68,0.83$, and 0.98 . It can be seen that the growth of blade displacements at $\psi=0^{\circ}$ for all test conditions is nearly linear, which means the blade was barely deformed. In contrast, the displacement growth at $\psi=270^{\circ}$ became quite nonlinear, indicating that there were great elastic deformations for the blade due to strong aerodynamic loads.

Figure 22 shows the comparison of the blade tip displacements between experimental and CSD results. The simulation results were also calculated with the CAMRAD software. As can be seen, the two results were in good agreement with each other in terms of magnitude and overall trend, and both of them obtained the maximum blade tip displacements near $\psi=270^{\circ}$. For the cases $\alpha \leq 0^{\circ}$, the displacement peaks of experimental results were slightly smaller than that of CSD results, and the difference got minimum when $\alpha=0^{\circ}$, which was only $1.27 \mathrm{~mm}$. For the cases $\alpha>0^{\circ}$, however, the maximum blade tip displacements of experi- mental results became larger than those of CSD results. It is noteworthy that there is a high-order harmonic in all CSD results. One possible reason is that the free wake-based nonuniform inflow model was used to calculate the blade displacements in the CAMRAD software. Besides, differences in the structure parameters between the simulation model and the actual blade could also lead to the harmonic.

4.3. Accuracy. Since the actual distances between any two blade targets or any two hub targets were known and nearly did not change during the experiments, the measurement accuracy in the current study could be evaluated by calculating the three-dimensional distances of the measured targets and comparing with the true values. Tables 2 and 3 list the measurement accuracy of different test conditions in hover and forward flight, respectively. The accuracy of hub targets was calculated based on the three-dimensional distances of surrounding targets from the central one, while the accuracy of blade targets was calculated based on the threedimensional distances between the two targets along the chordwise direction. As can be seen, the accuracy of the hub targets remained quite stable for all test conditions, and its average value was about $0.09 \mathrm{~mm}$. In contrast, the accuracy of the blade targets changed obviously as the test condition varied. For the hover flight conditions, with the increase of the collective pitch angle, the accuracy decreased gradually. Analogously, for the forward flight conditions, the same phenomenon occurred as the rotor shaft angle changes. The prime reason is that stereophotogrammetry usually obtains lower measurement accuracy in the $Z$-direction rather than in the $X Y$ plane. When the blade collective pitch angle or the rotor shaft angle changed, the relative 


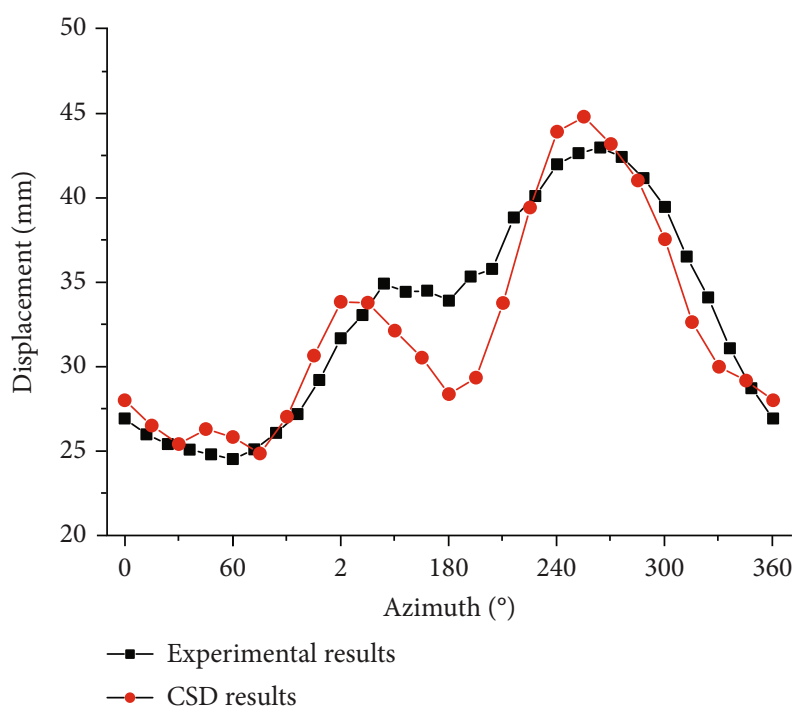

(a)

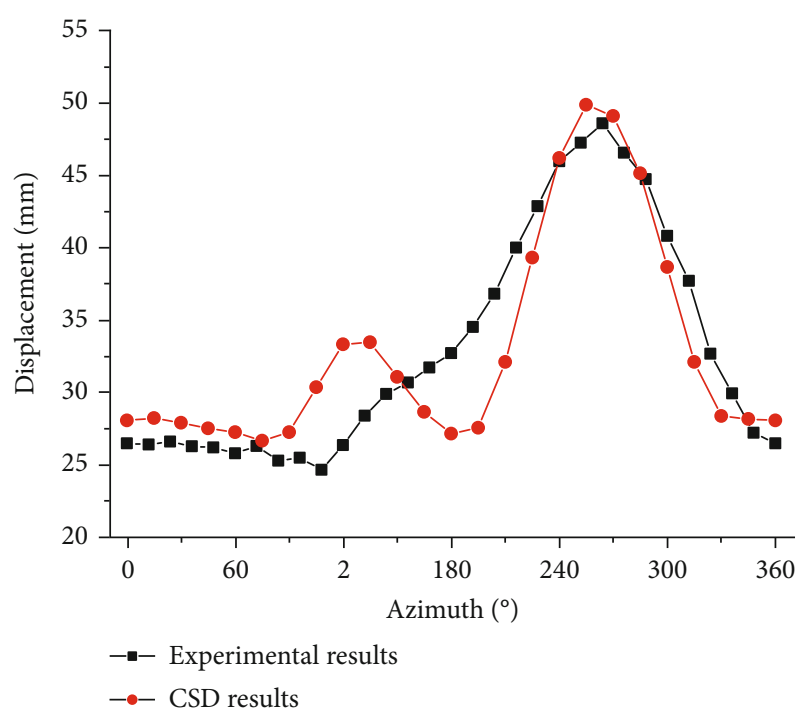

(c)

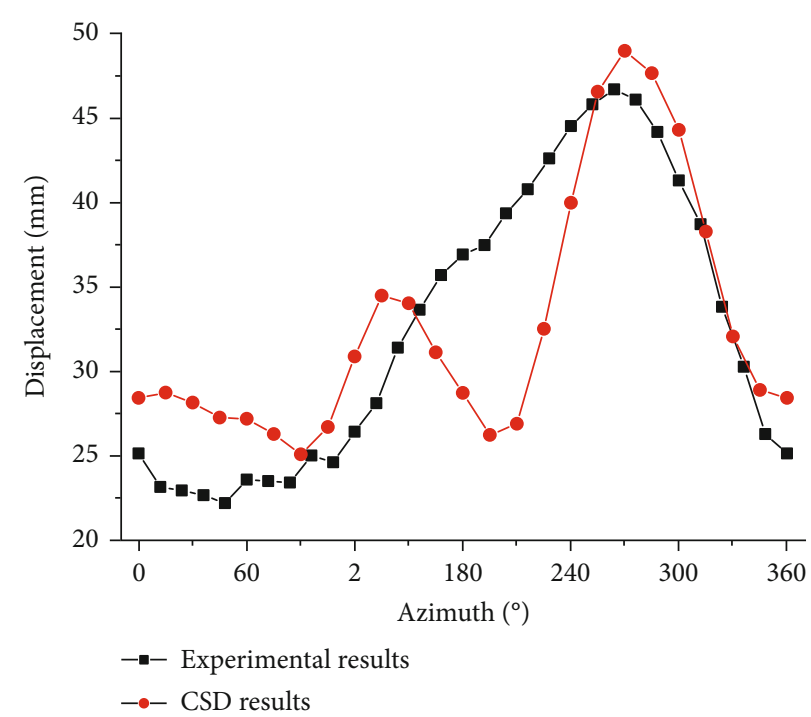

(b)

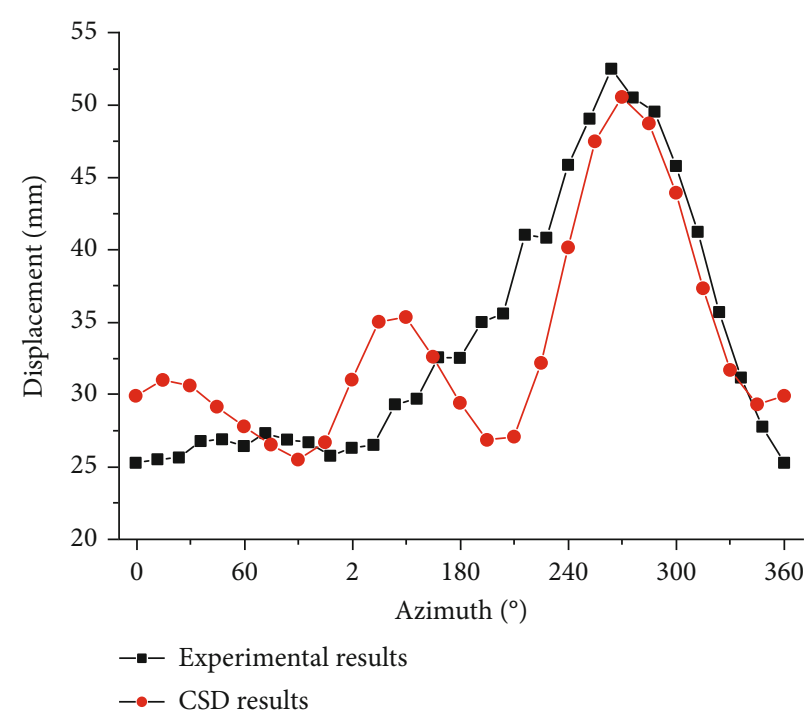

(d)

FIgUre 22: Continued. 


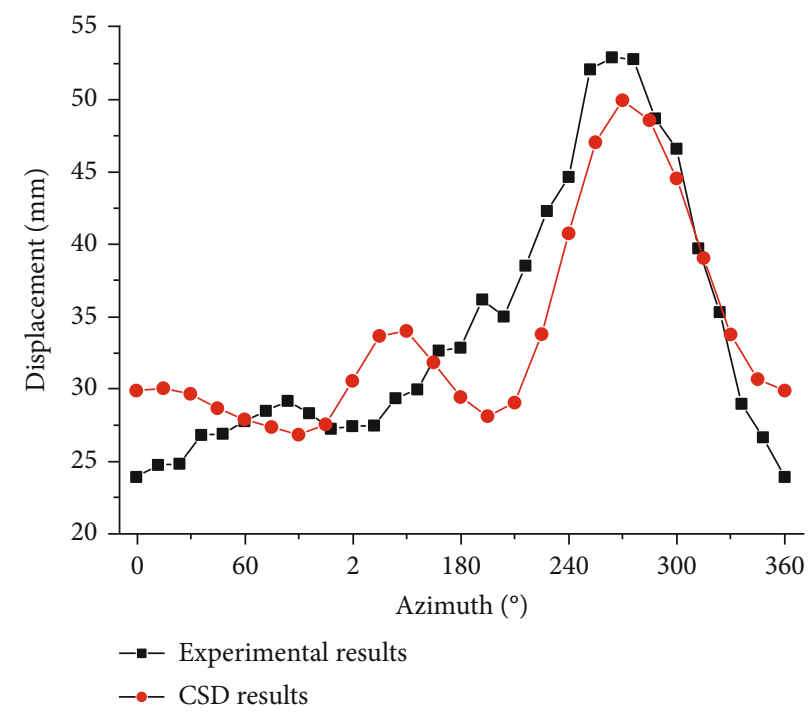

(e)

FIGURE 22: Comparison of the blade tip displacements between experimental and CSD results: (a) $\alpha=-4^{\circ}$; (b) $\alpha=-2^{\circ}$; (c) $\alpha=0^{\circ}$; (d) $\alpha=2^{\circ}$; (e) $\alpha=4^{\circ}$.

TABLE 2: Measurement accuracy in hover flight.

\begin{tabular}{lcc}
\hline$\theta\left({ }^{\circ}\right)$ & $\begin{array}{c}\text { Accuracy of hub targets } \\
(\mathrm{mm})\end{array}$ & $\begin{array}{c}\text { Accuracy of blade targets } \\
(\mathrm{mm})\end{array}$ \\
\hline 0 & 0.085 & 0.141 \\
2 & 0.082 & 0.157 \\
4 & 0.094 & 0.168 \\
6 & 0.099 & 0.194 \\
8 & 0.097 & 0.198 \\
Average & 0.091 & 0.172 \\
\hline
\end{tabular}

TABLE 3: Measurement accuracy in forward flight.

\begin{tabular}{lcc}
\hline$\alpha\left(^{\circ}\right)$ & $\begin{array}{c}\text { Accuracy of hub targets } \\
(\mathrm{mm})\end{array}$ & $\begin{array}{c}\text { Accuracy of blade targets } \\
(\mathrm{mm})\end{array}$ \\
\hline-4 & 0.103 & 0.256 \\
-2 & 0.089 & 0.132 \\
0 & 0.092 & 0.140 \\
2 & 0.088 & 0.175 \\
4 & 0.096 & 0.183 \\
Average & 0.094 & 0.177 \\
\hline
\end{tabular}

locations of blade targets became close to the $Z$-direction, and thus, the measurement accuracy went down. Besides, different blade deformation at each condition could also result in the loss of accuracy. The average accuracy of blade targets was about $0.17 \mathrm{~mm}$.

\section{Conclusions}

In the current study, a stereophotogrammetry approach has been developed to realize the full-field displacement measurements of helicopter rotor blades. To track the dynamic motion of the rotor shaft, a special hat was designed and installed directly above the rotor hub. Based on the targets arranged on the blade and the hub hat, the instantaneous locations of the blade at 30 azimuths over its full rotating range under different test conditions were measured and merged to the unified rotor coordinate system, where location deviations of the blade due to vibration of the measuring system or the rotor were corrected effectively and the blade displacements were calculated consistently. The proposed method has been validated in the wind tunnel test of a $2 \mathrm{~m}$ diameter rotor at a range of hover and forward fight conditions. The experimental results showed good agreements with the simulation results in terms of magnitude and trend. The average measurement accuracy is better than $0.2 \mathrm{~mm}$.

\section{Data Availability}

The data used to support the findings of this study are available from the corresponding author upon request.

\section{Conflicts of Interest}

The authors declare that they have no conflicts of interest.

\section{Acknowledgments}

This work is supported by the National Natural Science Foundation of China under grant 52006235.

\section{References}

[1] O. Kose and T. Oktay, "Simultaneous quadrotor autopilot system and collective morphing system design," Aircraft Engineering and Aerospace Technology, vol. 92, no. 7, pp. 10931100, 2020.

[2] T. Oktay and F. Sal, "Effect of the simultaneous variation in blade root chord length and blade taper on helicopter flight 
control effort," International Journal of Aerospace Engineering, vol. 2017, Article ID 6325269, 8 pages, 2017.

[3] T. Oktay and F. Sal, "Combined passive and active helicopter main rotor morphing for helicopter energy save," Journal of the Brazilian Society of Mechanical Sciences and Engineering, vol. 38, no. 6, pp. 1511-1525, 2016.

[4] N. Tourjansky and E. Szechenyi, "The measurement of blade deflections - a new implementation of the strain pattern analysis," in 18th European rotorcraft forum, Avignon, France, 1992.

[5] R. M. Kufeld, D. L. Balough, J. L. Cross, K. F. Studebaker, C. D. Jennison, and W. G. Bousman, "Flight testing the UH-60A airloads aircraft," in 50th Annual forum of the American helicopter society, Washington, USA, 1994.

[6] O. Schneider, "Analysis of SPR measurements from HART II," Aerospace Science and Technology, vol. 9, no. 5, pp. 409-420, 2005.

[7] F. K. Straub, V. R. Anand, B. H. Lau, and T. S. Birchette, "Wind tunnel test of the SMART active flap rotor," Journal of the American Helicopter Society, vol. 63, pp. 1-16, 2018.

[8] L. Olson, A. Abrego, D. Barrows, and A. Burner, "Blade deflection measurements of a full-scale UH-60A rotor system," in American helicopter socieity aeromechanics specialist conference, San Francisco, California, 2010.

[9] D. Barrows, L. Olson, A. Abrego, and A. Burner, "Blade displacement measurements of the full-scale UH-60A airloads rotor," in 29th AIAA Applied Aerodynamics Conference, Honolulu, Hawaii, June 2011.

[10] A. Abrego, L. Meyn, A. Burner, and D. Barrows, "Summary of full-scale blade displacement measurements of the UH-60A airloads rotor," in AHS technical meeting on aeromechanics design for vertical lift, San Francisco, California, 2016.

[11] C. Zuo, J. Ma, T. Yue, J. Song, and Z. Shi, "Blade displacement measurements of helicopter rotor based on stereo vision," in 18th International symposium on flow visualization, Zurich, Switzerland, 2018.

[12] G. Bernardini, J. Serafini, C. Enei, L. Mattioni, C. Ficuciello, and V. Vezzari, "Structural characterization of rotor blades through photogrammetry," Measurement Science and Technology, vol. 27, no. 6, article 065401, 2016.

[13] T. Lundstrom, J. Baqersad, and C. Niezrecki, "Monitoring the dynamics of a helicopter main rotor with high-speed stereophotogrammetry," Experimental Techniques, vol. 40, no. 3, pp. 907-919, 2016.

[14] Z. Dong, L. Liang, W. Zhang, L. Jiao, D. Peng, and Y. Liu, "Simultaneous pressure and deformation field measurement on helicopter rotor blades using a grid-pattern pressuresensitive paint system," Measurement, vol. 152, article 107359, 2020.

[15] J. Sirohi and M. S. Lawson, "Measurement of helicopter rotor blade deformation using digital image correlation," Optical Engineering, vol. 51, no. 4, article 043603, 2012.

[16] J. Sicard and J. Sirohi, "Measurement of the deformation of an extremely flexible rotor blade using digital image correlation," Measurement Science and Technology, vol. 24, no. 6, article 065203, 2013.

[17] B. Wei, J. Liang, H. Hu, M. Ren, H. Yi, and J. Li, “A videogrammetric system for measuring the full-field blade deformation of a heavy-duty helicopter's rotating rotor," Review of Scientific Instruments, vol. 89, no. 11, article 115111, 2018.
[18] D. Uehara and J. Sirohi, "Full-field optical deformation measurement and operational modal analysis of a flexible rotor blade," Mechanical Systems and Signal Processing, vol. 133, article 106265, 2019.

[19] D. Uehara, C. Johnson, and J. Sirohi, "Transient blade deformation and loads measurement of a coaxial rotor system," in AIAA Scitech 2019 Forum, San Diego, California, January 2019.

[20] P. J. Sousa, F. Barros, P. J. Tavares, and P. M. G. P. Moreira, "Displacement measurement and shape acquisition of an RC helicopter blade using digital image correlation," Procedia Structural Integrity, vol. 5, pp. 1253-1259, 2017.

[21] P. J. Sousa, F. Barros, P. J. Tavares, and P. M. G. P. Moreira, "Digital Image correlation displacement measurement of a rotating RC helicopter blade," Engineering Failure Analysis, vol. 90, pp. 371-379, 2018.

[22] P. J. Sousa, F. Barros, P. J. Tavares, and P. M. G. P. Moreira, "Displacement analysis of rotating RC helicopter blade using coupled CFD-FEA simulation and digital image correlation," Procedia Structural Integrity, vol. 17, pp. 812-821, 2019.

[23] P. Poozesh, J. Baqersad, C. Niezrecki, P. Avitabile, E. Harvey, and R. Yarala, "Large-area photogrammetry based testing of wind turbine blades," Mechanical Systems and Signal Processing, vol. 86, pp. 98-115, 2017.

[24] S. Lehnhoff, A. Gómez González, and J. R. Seume, "Full-scale deformation measurements of a wind turbine rotor in comparison with aeroelastic simulations," Wind Energy Science, vol. 5, no. 4, pp. 1411-1423, 2020.

[25] Z. Zhang, "A flexible new technique for camera calibration," IEEE Transactions on Pattern Analysis and Machine Intelligence, vol. 22, no. 11, pp. 1330-1334, 2000.

[26] S. Y. Gao, M. Zhao, L. Zhang, and Y. Zou, "Improved algorithm about subpixel edge detection of image based on Zernike orthogonal moments," Acta Automatica Sinica, vol. 34, no. 9, pp. 1163-1168, 2008. 